\title{
La percepción de los funcionarios municipales sobre la reforma de 2014 al Fondo de Aportaciones para la Infraestructura Social
}

\section{Perception of Municipal Officials about the 2014 Reform of the Social Infrastructure Fund}

Jorge Ibarra Salazar

\begin{abstract}
Resumen
En este artículo se presentan los resultados de una encuesta aplicada a una muestra de funcionarios municipales sobre la reforma del Fondo de Aportaciones para la Infraestructura Social (FAIS), que entró en vigor en 2014. El cuestionario fue aplicado durante el segundo trimestre de 20I5. Encontramos que la mayoría de los funcionarios municipales considera adecuadas las nuevas reglas de operación del FAIS. Las preocupaciones se refieren a la posible reducción de recursos asignados y la mayor complicación para acceder a los recursos. Se recomienda ampliar la difusión de la reforma para que la conozcan los funcionarios municipales e implementar una operación amigable para las administraciones municipales, que además sea consistente con los objetivos de transparencia y focalización plasmados en la reforma.
\end{abstract}

Palabras clave: FAIs, fórmula de asignación, ley de coordinación fiscal, encuesta, difusión de reforma

\begin{abstract}
In this paper, we present the results of a survey applied to a sample of municipal officials about the 2014 Reform of the Social Infrastructure Fund (FAIS). The questionnaire was applied during the second quarter of 2015. We found that the majority of city officials considered appropriate the new rules of operation of the FAIS. Their concerns relate to the possible reduction of resources allocated, and the further complication to access the funds. It is recommended to disseminate the reform to get city officials familiar with it, and implement a user-friendly operation for municipal administrations, that is also consistent with the objectives of transparency and focalization reflected in the reform.
\end{abstract}

Keywords: FAls, distribution formula, fiscal coordination law, survey, reform diffusion

- Doctor en Economía por la Southern Methodist University. Profesor asociado al Departamento de Economía del Tecnológico de Monterrey, E. Garza Sada 250I Sur. Col. Tecnológico. Monterrey NL 64849 (81) 8358-2000, ex. 4306. Orcid 0000-0002-958I-9099/_ jaibarra@tec.mx

Fecha de recepción: 9 de marzo de 2019. Fecha de aceptación: 5 de agosto de 2020. 


\section{Introducción}

Los municipios mexicanos reciben una transferencia federal cuyo propósito fundamental es que este orden de gobierno coadyuve con el gobierno federal a la reducción de la pobreza. El Fondo de Aportaciones para la Infraestructura Social (FAIS) fue instituido en 1998, y modificó el esquema negociado de asignación de transferencias condicionadas y con reciprocidad a través del Ramo 26 del presupuesto federal, denominado como de Superación de la Pobreza. Desde ese año se definieron las características del faIs en los artículos 32 a 35 de la Ley de Coordinación Fiscal (LCF). Esta Ley contiene el marco normativo de las transferencias del gobierno federal a los gobiernos estatales y municipales. Las participaciones federales, que son transferencias no-condicionadas, están contenidas en el capítulo I, mientras que las aportaciones federales, las transferencias condicionadas, en el capítulo v de la Ley. Además de las transferencias, la LCF regula también los organismos en materia de coordinación fiscal (capítulo IV) y la colaboración administrativa entre los distintos ámbitos de gobierno (capítulo III).

La primera reforma al FAIs fue aprobada para entrar en vigor en 2014. A iniciativa de la Secretaría de Desarrollo Social (sedesol), y con la aprobación del Congreso de la Unión, se modificó la integración, la fórmula de asignación y la operación del Fondo en forma importante. El surgimiento de nuevas formas de medir la pobreza, la mayor oportunidad en la disponibilidad de información, los incentivos perversos en el diseño de la fórmula de asignación, y un conjunto de vicios en la operación del FAIs motivaron la Reforma. Esta constituyó la primera modificación que se hizo al FAIs, desde su creación en 1998. Si acaso no existen motivaciones de orden político en la reforma, esta constituye una respuesta coordinada a la problemática que caracterizaba los dife- 
La percepción de los funcionarios municipales sobre la reforma de 2014 al Fondo de Aportaciones para la Infraestructura Social

rentes elementos del FAIs: la integración, la asignación y la operación.

En este artículo presentamos los resultados de una encuesta a una muestra de funcionarios municipales mexicanos sobre la reforma del FAIS en 2014. Las respuestas fueron captadas a través de un cuestionario que se les aplicó después del primer año de operación del nuevo esquema (en el segundo trimestre de 2015). La contribución de este estudio es que presenta la percepción de los funcionarios municipales justamente después de que el nuevo marco institucional fue aplicado. Presentamos las opiniones de los funcionarios sobre el grado en que se han alcanzado los objetivos planteados cuando se propuso y aprobó la citada Reforma. Los objetivos que se persiguieron con esta fueron la base que tomamos para el diseño de las preguntas.

La percepción de los funcionarios municipales reviste especial importancia, ya que son ellos los que están directamente involucrados en la operación del Fondo y la aplicación de los recursos financieros para los fines que fueron concebidos. El cumplimiento de los objetivos que se persigan con esta transferencia puede verse obstruido si acaso los municipios no están alineados con ellos, o si las reglas de operación no son lo suficientemente claras para la buena operación del Fondo. Conocer la percepción de los operadores municipales proporciona elementos a quienes diseñaron la reforma de 2014 para ajustar aquellos factores que constituyan áreas de oportunidad en el logro de los objetivos. Esta dimensión puede no ser evidente aplicando otras metodologías.

El estudio de Arellano et al. (2019) valora el funcionamiento del FAIS en 2015, después de la Reforma, y se centra en un municipio del estado de Jalisco, a través de entrevistas semiestructuradas a funcionarios encargados del Fondo, un grupo de enfoque con personas relacionadas con 
los procesos del Fondo y entrevistas con tres ciudadanos beneficiados con la obra financiada con el FAIs.

Encontramos que la mayoría de los funcionarios municipales considera adecuadas las nuevas reglas de operación del FAIs. Las únicas preocupaciones se refieren a la posible reducción de recursos asignados vía el FAIs y la mayor complicación para acceder a ellos. Se encontraron un área de oportunidad y un reto en la operación del nuevo esquema. La primera consiste en ampliar la difusión de la reforma para que la conozcan los funcionarios municipales. La segunda es implementar una operación amigable para las administraciones municipales que además sea consistente con los objetivos de transparencia y focalización plasmados en la reforma.

En la siguiente sección se discute la problemática del FAIS, en la tercera la metodología, la cuarta sección presenta los resultados y la sección final contiene nuestras conclusiones.

\section{Problemática del fals e hipótesis de trabajo}

Derivado del proceso de descentralización del gasto hacia los gobiernos locales, que se inició desde principios de los años ochenta, el gobierno federal mexicano institucionalizó la transferencia de recursos condicionados en 1998 a través del Ramo 33 del Presupuesto de Egresos de la Federación. Antes de la creación de las denominadas aportaciones federales, el gobierno central ejecutaba directamente estos recursos, o los transfería a estados y municipios a través de convenios y diferentes ramos presupuestarios.

Actualmente, el Ramo 33 está conformado por ocho fondos: i) Fondo de Aportaciones para la Educación Básica y Normal, ii) Fondo de Aportaciones para los Servicios de Salud, iii) Fondo de Aportaciones para la Infraestructura Social, iv) Fondo de Aportaciones para el Fortalecimiento de los Municipios y de las Demarcaciones Territoriales del 
Distrito Federal, v) Fondo de Aportaciones Múltiples, vi) Fondo de Aportaciones para la Educación Tecnológica y de Adultos, vii) Fondo de Aportaciones para la Seguridad Pública, y viii) Fondo de Aportaciones para el Fortalecimiento de las Entidades Federativas.

El FAIs es una transferencia federal de recursos etiquetados que deben destinarse al financiamiento de obras, acciones sociales básicas e inversiones que beneficien directamente a la población en extrema pobreza y con alto grado de rezago social (agua potable, alcantarillado, drenaje y letrinas, urbanización municipal, electrificación rural y de colonias pobres, infraestructura básica de salud y educativa, mejoramiento de vivienda, caminos rurales e infraestructura productiva rural).

Hasta antes de la reforma, el FAIs se integraba con el $2.5 \%$ de la recaudación federal participable: El 0.303\% iba para los estados y el $2.197 \%$ a los municipios. Se distribuía a las entidades federativas de acuerdo con la masa carencial, la cual se calculaba con el Índice Global de Pobreza y el número de miembros en el hogar en pobreza extrema. A su vez, las entidades federativas distribuían el FAIs a sus respectivos municipios aplicando la misma fórmula, con la previsión contenida en el artículo 35 de la LCF.

A pesar de que la creación del FAIs significó una mayor participación de los gobiernos locales en la creación de proyectos de infraestructura social básica, la forma de operación del Fondo presentaba diversos problemas.

El Centro de Estudios de las Finanzas Públicas de la Cámara de Diputados (CEFP) apunta que los recursos del FAIs habían sido destinados a fines diferentes a los establecidos, que había obras pagadas no ejecutadas, que faltaban comprobantes de gastos, que había deficiencias técnicas en las obras, pagos en exceso por gastos indirectos, recursos no entregados a los municipios, entre otros (CEFP, 2005 y 2009). La Auditoría Superior de la Federación (ASF) señala 
que en la revisión de la Cuenta Pública 2009 de los municipios, el desvío de recursos de este Fondo se distribuyó de la siguiente manera:

a. $28.5 \%$ debido al financiamiento de obras que no beneficiaron a la población en rezago social y pobreza extrema;

b. $28.4 \%$ debido al financiamiento de obras y acciones no comprendidos en los rubros que establece la LCF;

c. $21.2 \%$ debido al traspaso de recursos a otros programas o cuentas del municipio y que no fueron reintegrados en su totalidad;

d. $13.3 \%$ debido a la falta de documentación comprobatoria del gasto;

e. $4 \%$ debido a irregularidades relacionadas con obra pública, $\mathrm{y}$

f. $3.2 \%$ debido a recursos ejercidos por encima del límite establecido para gastos indirectos o para el Desarrollo Institucional (INAFED, 2011).

El CONEVAL (2011) informa que los funcionarios municipales no conocían la fuente de información de las variables que se empleaban en el cálculo de los montos distribuidos por el gobierno federal. Tanto la SHCP (2010) como el INAFED (2011) hacen notar el rezago de la información utilizada para calcular el Índice Global de Pobreza, ya que se venía actualizando cada diez años.

La SHCP (2010) consideraba necesario modificar las variables, los criterios y las fórmulas de reparto del FaIs, ya que, de acuerdo con los funcionarios municipales entrevistados en su estudio, estos no contribuyen al cumplimiento del propósito del Fondo. Asimismo, la ASF recomendaba la revisión y ampliación de la apertura programática del Fondo, pues consideraba que esta ya no era adecuada a los requerimientos actuales de los municipios (INAFED, 2011). 
La percepción de los funcionarios municipales sobre la reforma de 2014 al Fondo de Aportaciones para la Infraestructura Social

En cuanto al impacto de la inversión en infraestructura social, los estudios del Centro de Investigación para el Desarrollo (2003), Díaz Cayeros y Silva (2004), CEPAL (2004) y CEFP (2007) indicaban que tanto el monto transferido a través del FAIS como su incremento habían tenido un efecto muy débil y limitado, confirmando de esa forma la percepción de los funcionarios consultados en el estudio de la SHCP (2010). Relacionado con esto, De la Torre (2005) ha demostrado que la distribución del gasto federal descentralizado no está completamente ligada al rezago de las entidades federativas, pues algunos estados con grandes necesidades de desarrollo reciben una asignación menor de recursos que estados con un bajo nivel de rezago social.

En cuanto al destino de los recursos, los estados no se basaban en un catálogo para decidir a qué obra se aplicará el recurso, sino solo por la condición de que su alcance fuera regional o intermunicipal (Barceinas y Monroy, 2002). En el mismo sentido, el CEFP (2009) señala que era difícil evaluar el impacto del Fondo, ya que los estados tenían una gran diversidad de opciones para la aplicación de los recursos. Por su parte, Hernández y Jarillo (2007) reconocen que existía cierto margen de discrecionalidad en la asignación del Fondo, tanto de los estados a sus municipios, como dentro de interior de estos. También apuntan que las cabeceras municipales eran las que recibían la mayor parte de los recursos.

Otros autores destacan la falta de precisión de las reglas de operación del FAIs, la falta de transparencia y la nula rendición de cuentas a los ciudadanos (Moreno, 2007; Cejudo y Gerhard, 2009). También se señala un insuficiente control del Fondo, así como sistemas de contabilidad y mecanismos de evaluación débiles (SHCP, 2010; INAFED, 2011; Wellenstein et al., 2006). Esta situación impedía la verificación de la correcta aplicación de recursos, la identificación del impacto de las obras en la población pobre y los logros alcanzados (CEFP, 2009). 
Sour y Ortega (2008) apuntan que la mayoría de las entidades federativas no consideraba disposiciones específicas sobre el calendario y la distribución de los recursos del FAIS a sus municipios en su marco legal.

El estudio de Ruíz Porras y García Vázquez (2014) sugiere que la asignación de las transferencias a los municipios del estado de Jalisco en el período 2005-2011, incluyendo participaciones y aportaciones federales, ha obedecido a criterios políticos, representados por la filiación política de los alcaldes. Por su parte, Vázquez Elorza y Reyes Munguía (2014), en su estudio sobre la fórmula de asignación del FAIS en el estado de San Luis Potosí, tienen como hipótesis que los recursos del FAIs incorporan incentivos contrarios a los objetivos de la Ley de Coordinación Fiscal. También consideran que los municipios no tienen sistemas de evaluación de gestión de los programas, así como indicadores de resultados. Anotan que los municipios no cuentan con información actualizada para medir la pobreza, y les faltan indicadores estandarizados para medir el desempeño del fondo, incentivos y buena gestión.

También se ha argumentado que la fórmula de reparto del FAIS generaba incentivos perversos: por un lado, se encuentra el desincentivo a la recaudación local, pues, al contar con el apoyo mensual de este Fondo, los gobiernos municipales no realizan un gran esfuerzo recaudatorio (Moreno, 2007); por otro lado, el desincentivo a la reducción de la pobreza, ya que la fórmula asigna más recursos al más pobre, por lo que el gobierno local no tiene incentivo para erradicar la pobreza (Michel, 2003). Ibarra Salazar (2018) presenta un modelo de información asimétrica que fundamenta la fórmula de reparto del FAIS que se ha estado usando a partir de 2014.

Ramones y Prudencio (2014), con datos a escala estatal, muestran evidencia empírica de que el FAIs no ha influido en las variaciones en distintos indicadores de pobreza. Explican que esta falta de influencia del fondo en los niveles de 
La percepción de los funcionarios municipales sobre la reforma de 2014 al Fondo de Aportaciones para la Infraestructura Social

pobreza puede explicarse por los incentivos contenidos en la fórmula de asignación del Fondo, o porque la cuantía del fondo es insuficiente para lograr reducirla.

Otros problemas que se encontraron fueron: subejercicio de fondos, falta de participación social por parte de la población beneficiaria, irregularidades en los procesos de licitación, adjudicación y contratación de obras y adquisiciones, entre otros (INAFED, 2011).

Esta problemática motivó la reforma del FAIS, con el objeto de corregir, entre otras, las siguientes deficiencias:

1. Los incentivos perversos en el mecanismo de asignación del FAIS. La nueva forma de asignación del Fondo cuenta con tres componentes: $i$ ) el número promedio de carencias de la población en pobreza extrema, que permitirá asignar más recursos a las entidades y los municipios más pobres; ii) la eficiencia en la reducción de la pobreza extrema, que recompensa a las entidades y los municipios que logren reducir la población en pobreza extrema y rezago social, y iii) se garantiza un monto fijo igual al que recibió el estado o municipio por este concepto en el año 2013. La nueva fórmula solo se aplica al excedente sobre el valor nominal del Fondo del año actual con respecto al anterior.

2. La oportunidad en la información. Ahora se usa la información de pobreza extrema más reciente a escala estatal y municipal publicada por el CONEVAL. Se actualiza cada dos años para los estados y cada cinco años para los municipios.

3. La focalización geográfica. La SHCP deberá generar un sistema geo referenciado para difundir —a través de su página de Internet- las obras financiadas con este Fondo en cada municipio.

4. La transparencia en la distribución, el destino y el ejercicio de los recursos del Fondo. Con la reforma: i) los municipios deben presentar informes relacionados 
con el uso de los recursos a las delegaciones estatales de la SEDESOL y la SHCP; ii) la SEDESOL debe publicar un informe anual sobre la situación de pobreza y rezago social que sirva como guía para determinar obras prioritarias, y iii) la SEDESOL debe listar el destino de los recursos del Fondo por grandes rubros, con el objeto de establecer claridad en estos.

Sobre la base de la problemática expuesta, en este artículo definimos cuatro hipótesis de trabajo:

- Hipótesis 1 (incentivos). La mayoría de los funcionarios municipales considera que la nueva fórmula de asignación del FAIs incentiva a reducir la pobreza.

- Hipótesis 2 (información). La mayoría de los funcionarios municipales considera que la información que se utiliza en la fórmula de asignación del FAIs es más oportuna.

- Hipótesis 3 (focalización). La mayoría de los funcionarios municipales considera que con el nuevo esquema para operar el faIs los recursos estarán mejor focalizados.

- Hipótesis 4 (transparencia). La mayoría de los funcionarios considera que el nuevo esquema de reparto del FAIS mejora la transparencia en la distribución y el destino de los recursos y mejora el ejercicio de los recursos del Fondo.

Las hipótesis responden a los principales objetivos de la reforma, a partir de la exposición de motivos correspondiente. ${ }^{1}$ Esta, a su vez, tiene como base los estudios, las evaluaciones y los diagnósticos presentados en esta sección. Siendo la información empleada para asignar los fondos más oportuna, si a través de la fórmula se asigna una mayor cuantía en la medida que se reduzca el indicador de pobreza empleado, sería congruente esperar que la administración 
municipal tenga incentivos para que se reduzca la pobreza en su ámbito geográfico de operación. De esa forma también, se esperaría que los esfuerzos en la aplicación de los recursos estuvieran dirigidos a infraestructura social que reduzca el indicador de pobreza.

\section{Metodología}

Las preguntas en el cuestionario diseñado para los funcionarios municipales requieren que se responda en afirmativo o negativo. ${ }^{2}$ Para determinar el tamaño de la muestra, denotamos las respuestas afirmativas de un reactivo como $x, P$ a la proporción poblacional de respuestas afirmativas, y $N$ el número de elementos de la población. Supondremos que $x$ sigue una distribución binomial con parámetros $N$ y $P$, donde la proporción $P$ es desconocida, pero puede ser estimada como $p=x / n$, y siendo $n$ el número de elementos en la población que habrán de entrevistarse (el tamaño de la muestra). El intervalo estimado con un nivel de confianza de $(1-\alpha)$ para la proporción $p$, usando la corrección de una población finita es:

$p \pm z_{1-\alpha} \sqrt{\frac{p(1-p)}{n}} \sqrt{\frac{N-n}{N-1}}$

El error, $e$, tal que $\operatorname{Pr}(|P-p|<e)=1$ - $\alpha$, es:

$e=z_{1-\alpha} \sqrt{\frac{p(1-p)}{n}} \sqrt{\frac{N-n}{N-1}}$

2. El cuestionario está disponible para el lector interesado. No se incluye aquí por razones de espacio. 
Resolviendo la expresión (2) para $n$ se obtiene: ${ }^{3}$

$$
n=\frac{N n_{0}}{N-1+n_{0}}
$$

donde

$$
n_{0}=\frac{z_{1-\alpha}^{2} p(1-p)}{e^{2}}
$$

sería el tamaño de la muestra cuando no se considera la corrección del tamaño de la población.

A partir de (3), la probabilidad de que la diferencia entre la proporción de respuestas positivas de la población y la estimada con la proporción muestral sea menor al margen de error es igual al nivel de confianza. Si el error es 5.3\%, el nivel de confianza 95\%, suponiendo que las proporciones de elementos de la muestra que responden afirmativa y negativamente son iguales $(p=1-p=0.5)$, y dado que el número de municipios es $N=2,438$, entonces la muestra es $n=299.96$.

Bajo las condiciones del teorema del límite central, la proporción estimada $(p)$ sigue una distribución normal con media igual a $P$ y varianza igual a $P(1-P) / n$. El estadístico de prueba para realizar inferencia estadística sobre proporciones se calcula como:

$$
z=\frac{p-P}{\sqrt{P(1-P) / n}}
$$

3. Ver Fleming y Nellis (2000), y también material publicado en Internet sobre la distribución de probabilidad y tamaño muestral de proporciones que son binomiales. http://www.uv.es/iarribas/wikibase/Varios/esicart.pdf, http://courses. wcupa.edu/rbove/Berenson/I0th\%20ed\%20CD-ROM\%20topics/section8_7.pdf, http://www.feedbacknetworks.com/cas/experiencia/sol-preguntar-calcular.html. 
La percepción de los funcionarios municipales sobre la reforma de 2014 al Fondo de Aportaciones para la Infraestructura Social

Uno de los asuntos que es importante en el análisis de resultados es la consideración de los diferentes niveles de desarrollo de los municipios. Por eso estratificamos la muestra para incluir municipios en todos los niveles de desarrollo. El nivel de desarrollo municipal lo aproximamos con el ingreso per capita municipal. De acuerdo con Ibarra Salazar et al. (2013, p. 152),

Si bien el Instituto Nacional de Estadística Geografía e Informática (INEGI) produce estadísticas de la producción estatal, no cuenta con estadísticas sobre la producción municipal. Estudios previos, sin embargo, han estimado la producción municipal siguiendo diferentes métodos para imputar a los municipios la producción estatal. Suponiendo que la productividad laboral es igual en los municipios, Sánchez (2000) y Unikel et al. (1976) utilizan la población ocupada; Ibarra Salazar y Mollick (2006) el ingreso de la población ocupada; y Anderson y Gerber (2008) usan la composición sectorial de la producción y el empleo del censo económico.

En este estudio utilizamos la estimación del ingreso municipal empleada por el Programa de las Naciones Unidas para el Desarrollo de México, PNud (2014). Esa estimación toma como base la metodología de imputación del ingreso sobre la base del Censo General de Población y Vivienda de 2000 y la Encuesta Nacional de Ingresos y Gasto de los Hogares (ENIGH) expuesta en Székely et al. (2007). ${ }^{4}$

Para asegurar que los diferentes estratos de ingreso municipal fueran cubiertos, formamos seis grupos de igual número de municipios, de acuerdo con el nivel del ingreso municipal per capita. El cuadro 1 resume la conformación de los grupos.

Para realizar el trabajo de campo se contrató a la empresa INMEGA Investigación de Mercados SC (Disponible en: http:// www.inmega.com/). El número de entrevistas que se soli-

4. Estos datos se pueden consultar también en el sitio del INAFED, Sistema Nacional de Información Municipal. Disponible en: snim.rami.gob.mx. 
citaron fue, de acuerdo con el tamaño de muestra, 300; se indicó también que a cada grupo se le administraran 50 para, asegurar igual cobertura de los seis grupos de municipios, de acuerdo con su nivel de desarrollo.

Por la complejidad y la longitud del cuestionario, su administración exigió múltiples intentos, hasta concertar la entrevista con el funcionario adecuado, y también requirió varias sesiones con el funcionario para obtener las respuestas a todas las preguntas. El proceso implicó el trabajo de los encuestadores en forma simultánea para obtener el máximo de respuestas en cada grupo de municipios en un tiempo limitado. El trabajo de campo se realizó en el segundo trimestre de 2015. A la fecha de corte del trabajo de campo (25 de julio de 2015), se aplicaron 284 cuestionarios válidos. El número de cuestionarios válidos en cada grupo de municipios aparece en la última columna del cuadro $1 .{ }^{5}$

El instrumento utilizado para el trabajo de campo, que aparece en el anexo, consta de cinco partes. En la primera parte se considera la opinión de los entrevistados con respecto a las características del FAIS, tal como son expuestas en la LCF. Estas características se refieren a la integración del Fondo, cómo se entera, su destino, los mecanismos de transparencia y la fórmula de asignación. El objetivo de las preguntas en la segunda parte es conocer la percepción de los entrevistados con respecto al impacto sobre la pobreza de los diferentes programas, acciones y áreas en que se asignan los recursos del FAIs, y si hay otros programas que pueden ayudar a reducir la pobreza. El objetivo de la tercera sección es saber si los municipios miden resultados e impactos y cómo lo hacen. También interesa saber si evalúan los programas asociados con el FAIs y les dan seguimiento. En la cuarta sección se obtiene la opinión de los entrevistados sobre el método y la fórmula de asignación del FaIs y sobre la lector interesado. No se incluye aquí por razones de espacio. 
La percepción de los funcionarios municipales sobre la reforma de 2014 al Fondo de Aportaciones para la Infraestructura Social

conveniencia de haber modificado la fórmula de distribución y de haber incluido la eficacia en la reducción de la pobreza como criterio de reparto. Igualmente se pregunta sobre los incentivos perversos. Se registra también la percepción del entrevistado sobre el incentivo que puede generar el diseño de la fórmula al incorporar la magnitud de la pobreza.

A efectos del presente estudio, la quinta parte es relevante. Su objetivo es tener la percepción del entrevistado sobre un conjunto de aseveraciones relativas a la nueva fórmula de asignación del FAIs. En buena medida, las aseveraciones fueron tomadas de la exposición de motivos para la reforma de la fórmula de asignación del FAIs que operó durante 2014 (cuadro 2).

Cuadro 1. Conformación de los grupos de municipios de acuerdo con el ingreso per capita

\begin{tabular}{cccc}
\hline Grupo & $\begin{array}{c}\text { Número de } \\
\text { municipios }(n)\end{array}$ & $\begin{array}{c}\text { Rango de ingreso } \\
\text { per capita }(\$)\end{array}$ & $\begin{array}{c}\text { Número de } \\
\text { Entrevistadas }\end{array}$ \\
\hline 1 & 406 & Entre 58,170 y 240,000 & $49(17 \%)$ \\
2 & 406 & Entre 46,000 y 58,170 & $55(19 \%)$ \\
3 & 406 & Entre 36,990 y 46,000 & $50(18 \%)$ \\
4 & 406 & Entre 30,560 y 39,990 & $60(21 \%)$ \\
5 & 407 & Entre 24,380 y 30,560 & $46(16 \%)$ \\
6 & 407 & Entre 10,300 y 24,380 & $24(8 \%)$ \\
Total & 2,438 & & 284 \\
\hline
\end{tabular}

Fuente: Construcción propia sobre la base de PNUD (2014).

\section{Resultados}

Para estudiar la percepción de los funcionarios municipales, sobre la base del Decreto publicado en el DOF se tomó un conjunto de aseveraciones con respecto a los propósitos y aspectos que se corregirían del esquema operado hasta 2013. Para cada aseveración se solicitó al funcionario entre- 
vistado si estaba completamente de acuerdo, de acuerdo, en desacuerdo o completamente en desacuerdo. Para el cálculo de los estadísticos de prueba del cuadro 3 , tomamos la suma de los porcentajes de respuesta de las primeras dos opciones para determinar el porcentaje de respuestas afirmativas.

Dado que las administraciones municipales operaron esta reforma durante 2014, este es el primer esfuerzo sistemático por obtener un diagnóstico de la reforma de 2014. El cuadro 2 contiene los resultados que se comentan en esta sección, y el cuadro 3 muestra los estadísticos de prueba con que analizamos nuestras hipótesis de trabajo.

Respecto de la pregunta “¿Conoce los cambios en la LCF que entraron en vigor a partir del $1^{\circ}$ de enero de 2014 con relación al faIs?", 141 de los funcionarios municipales entrevistados dijeron sí conocerlos, lo que equivale al 49\%, mientras que 143 respondieron que no los conocen. Del $40 \%$ que respondió que sí, el grupo 1 fue el que tiene mayor conocimiento a los cambios en la LCF, ya que el 57\% de los funcionarios entrevistados en ese grupo aseguraron estar al tanto de dichas modificaciones. Por su parte, del grupo 5, solo el 37\% de los municipios dijeron conocer los cambios en la LCF; este es el más bajo del total de los seis grupos. Este resultado es consistente con el estudio de caso de Arellano et al. (2019: p. 22). A partir de sus entrevistas ellos comentan:

la federación y el gobierno estatal no ofrecen al municipio el acompañamiento necesario en los procesos, y si bien los colaboradores de este último se encuentran familiarizados con la operación del Fondo, cambios recientes en su reglamentación demostraron que la actualización y la capacitación en los nuevos lineamientos no llegó a todos por igual, por lo tanto, se incurrió en incumplimiento por omisión y desconocimiento.

Para el resto de las preguntas del cuestionario solo se tomó en consideración al 49\% de los municipios que dijo conocer los cambios en la LCF con relación al FAIs. A este grupo se 
La percepción de los funcionarios municipales sobre la reforma de 2014 al Fondo de Aportaciones para la Infraestructura Social

le presentó un conjunto de afirmaciones relacionadas con la nueva fórmula y el nuevo esquema para operar del fais. Comenzando con las aseveraciones basadas en la nueva fórmula de asignación del FAIs, se observa en el cuadro 2 que el $86 \%$ de los funcionarios entrevistados concuerda con que la nueva fórmula incentiva a reducir la pobreza en el municipio, mientras que el $14 \%$ no lo considera así. De este último porcentaje, el $22 \%$ corresponde a municipios del grupo 4; este bloque es de quienes menos consideran que la nueva fórmula de asignación del FAIs incentiva la disminución de pobreza. La hipótesis 1 , relacionada con los incentivos de la nueva fórmula, postula que la mayoría de los funcionarios considera que la nueva fórmula incentiva a reducir la pobreza. De acuerdo con el estadístico de prueba que aparece en el cuadro 3, existe evidencia que nos conduce a aceptar dicha hipótesis.

A continuación se preguntó a los funcionarios municipales si consideran que la nueva fórmula del FAIs mejora la distribución de los recursos, y el 72\% dijo estar de acuerdo con esta aseveración. Del 27\% restante, el 59\% de los municipios en el grupo 6, que corresponde al grupo con el ingreso per capita más bajo, dijo estar en desacuerdo con que la nueva fórmula mejora la distribución de los recursos del FAIs. Esto contrasta con el grupo 5, un nivel per capita inmediatamente mayor al del grupo 6, puesto que el grupo 5 contiene el porcentaje más alto de municipios que consideran que la fórmula del FAIS mejora la distribución de recursos (88\%).

Por el otro lado, se preguntó a los funcionarios municipales si creen que con la nueva fórmula se mejora el ejercicio de los recursos del FAIS, a lo que el $82 \%$ de los entrevistados respondió en afirmativo. Este resultado, tomando el estadístico de prueba en el cuadro $3(\mathrm{z}=7.57)$, confirma la hipótesis 4, en el sentido de que una mayoría de funcionarios municipales considera que la nueva fórmula de asignación mejorará el ejercicio de los recursos del FAIs. Además de 
esto, los mayores porcentajes de respuestas que dijeron estar de acuerdo con esta aseveración y en desacuerdo se encuentran en los grupos 5 y 6 , respectivamente. Es decir, que el $95 \%$ de los municipios del grupo 5 considera que la nueva fórmula mejora el ejercicio de recursos del Fondo, mientras que los funcionarios en los municipios del grupo 6, con el ingreso per capita más bajo, están en desacuerdo con esta idea.

En cuanto a la pregunta de si la nueva fórmula refuerza los objetivos de creación del FAIs, el 83\% de los funcionarios entrevistados estuvo de acuerdo con esta afirmación. Del grupo 2, el 90\% dijo concordar con esa idea, mientras que del grupo 6 casi la mitad (42\%) de los entrevistados rechazó la aseveración. Asimismo, el 86\% de los funcionarios encuestados consideró que la nueva fórmula asegura un mejor uso de los recursos del faIs. Sobre esta afirmación, el 100\% de las respuestas que conforman el grupo 5 dijo estar de acuerdo, mientras que en el resto de los grupos el rango de aceptación a la pregunta se encuentra entre el $75 \%$ y el $90 \%$.

Consecuentemente, el cuadro 2 muestra que el $84 \%$ de los municipios considera que la nueva fórmula de asignación del FAIS asegura una mayor transparencia en la distribución de los recursos a las entidades federativas y municipios. De acuerdo con el estadístico de prueba que se muestra en el cuadro $3(\mathrm{z}=8.05)$, este porcentaje estimado muestra evidencia de que el poblacional debe ser mayor al 50\%, con lo que existe evidencia de que la mayoría de los funcionarios municipales considera que el nuevo esquema de reparto del FAIS asegura una mayor transparencia en la distribución de los recursos a estados y municipios. Esto confirma una parte de la hipótesis 4 . Además, respecto de esta pregunta, no se observaron extremos entre los diferentes grupos de municipios, ya que el menor porcentaje de aceptación fue del 75\% desplegado para el grupo 1, y alcanzó el 100\% en el grupo 5. 
La percepción de los funcionarios municipales sobre la reforma de 2014 al Fondo de Aportaciones para la Infraestructura Social

Por el otro lado, el 50\% de los municipios considera que la nueva fórmula reducirá los recursos financieros a los municipios más pobres. Con excepción del grupo de municipios con ingreso per capita más alto, el resto de los aglomerados considera que esto sucederá una vez que se aplique la nueva fórmula de asignación del FAIs.

La siguiente aseveración indica que la nueva fórmula establece con claridad el destino de los recursos, en lo que el $85 \%$ de la muestra estuvo de acuerdo. Dado que, de acuerdo con este porcentaje de respuesta, el estadístico de prueba es $z=8.28$ (cuadro 3), entonces se confirma la parte de la hipótesis 4 que trata sobre el destino de los recursos del FAIs. En este caso, el grupo de municipios que se caracteriza por el mayor ingreso per capita mostró el menor porcentaje de municipios que concordaban con la premisa, mientras que el resto mostró un rango de aceptación entre el 80\% y 100\%.

Ahora bien, el 83\% de la muestra que conoce la reforma de 2014 considera que la nueva fórmula hace previsible que se obtengan mejores resultados en la aplicación de recursos. En este apartado el grupo 1 y el grupo 6 de municipios, los cuales representan a municipios con el ingreso per capita más alto y el más bajo, respectivamente, fueron los que mostraron el porcentaje de desaprobación más alto a la afirmación presentada (de 33\%), aunque aún por debajo del nivel de aprobación en estos grupos.

Respecto de la eficiencia en el ejercicio de los recursos, solo el 11\% de la muestra considera que la nueva fórmula no generará una mejora en el ejercicio de los recursos otorgados por el FAIS. Asimismo, en promedio, el 70\% de los funcionarios encuestados considera que con la nueva fórmula es más clara la asignación de fondos a estados y municipios.

El 83\% de los funcionarios municipales encuestados, y que dijeron conocer las reformas a la LCF con respecto al FAIS, considera que la información empleada con la nueva fórmula es más oportuna. De acuerdo con el estadístico de 
prueba en el cuadro $3(\mathrm{z}=7.81)$, este porcentaje de respuesta es significativamente mayor del $50 \%$, con lo que probamos la hipótesis 2 con relación a la oportunidad de la información. Es interesante anotar, sin embargo, que los grupos 1 y 3 tienen en promedio el $25 \%$ de respuestas en desacuerdo con esta proposición.

En cuanto al monto de recursos recibidos por las entidades y municipios, se preguntó si perciben que el monto nominal ha disminuido a raíz de la nueva fórmula del FAIs. Poco más de la mitad de los municipios respondió que sí; los grupos 3, 4 y 5 mostraron porcentajes de más del 60\% que opina de esta manera. Por el otro lado, el grupo de ingreso per capita más bajo (grupo 6) no considera que el monto nominal recibido haya disminuido con la nueva fórmula, hecho que se esperaba dada la finalidad de la reforma al FAIS. Como se observa en el cuadro 2, estos resultados son muy similares a los obtenidos con la siguiente aseveración, en la que se hace referencia al monto real recibido por los gobiernos locales.

El 54\% del total de los municipios que conocen los cambios en la LCF considera que con la nueva fórmula será más sencilla la operación de los recursos. Sobre este punto, el $65 \%$ de los funcionarios del grupo 1 se mostró en desacuerdo con la aseveración. Igualmente, 84 de 140 municipios (60\%) opinan que a raíz de la reforma en la fórmula del FAIS será más fácil bajar los fondos federales. De los que están en desacuerdo, resaltan los últimos tres grupos con menor ingreso per capita municipal, pues casi la mitad de los ayuntamientos que los integran considera que no será más sencilla la transferencia de recursos de la federación hacia los diferentes ámbitos de gobierno estatal y municipal. No obstante lo anterior, más del $80 \%$ de los funcionarios entrevistados en todos los grupos denotó que con el nuevo esquema la operación del FAIs ser más transparente. 
La percepción de los funcionarios municipales sobre la reforma de 2014 al Fondo de Aportaciones para la Infraestructura Social

Respecto de la focalización de los recursos con cargo al FAIS, solo el 17\% no está de acuerdo con que con el nuevo esquema de reparto se focalizarían mejor los recursos para reducir la pobreza. De esta muestra, el grupo 1 superó al promedio, al tener el $36 \%$ de los funcionarios municipales en desacuerdo con esta aseveración. Por el otro lado, el $78 \%$ de los funcionarios opina que con el nuevo esquema de operación del faIs los fondos serán más predecibles, de manera que facilitarán la planeación municipal. La hipótesis 3 considera que, con el nuevo esquema para operar el FAIs, la mayoría de los funcionarios municipales considera que se mejoraría la focalización de los recursos del FAIs en reducir la pobreza. De acuerdo con el porcentaje de respuestas afirmativas (83\%), el estadístico de prueba en el cuadro 3 confirma esta hipótesis.

En cuanto a la percepción de que el nuevo esquema para operar del FAIs beneficiaría a los municipios más pobres, el $35 \%$ de los funcionarios municipales consideró que esto no sucederá; incluso, el grupo de menor ingreso per capita fue el que mostró el porcentaje más alto de nivel de desacuerdo con esta aseveración (41\%).

Otro punto a destacar es que el 72\% de los funcionarios considera que se han generado obstáculos y barreras en los municipios más desarrollados. Asimismo, poco más de la mitad de los entrevistados también opina que se han creado barreras en los municipios más pobres. En ambos aciertos, el grupo 6 es el que registró mayor nivel de aprobación con estas aseveraciones, con el $75 \%$ de funcionarios.

Por último, se pidió la opinión respecto de si consideran que con el nuevo esquema para operar del FAIs se han generado obstáculos en municipios rurales y urbanos. Aunque los porcentajes de respuesta son similares para todos los grupos en ambas preguntas, en cuanto a municipios urbanos se refiere, el nivel de aprobación con la aseveración es 
ligeramente superior con respecto a los municipios rurales (63\% vs $55 \%)$.

Cuadro 2. Opiniones de funcionarios municipales con respecto a la reforma de 2014 del FAIS por grupo (porcentajes)

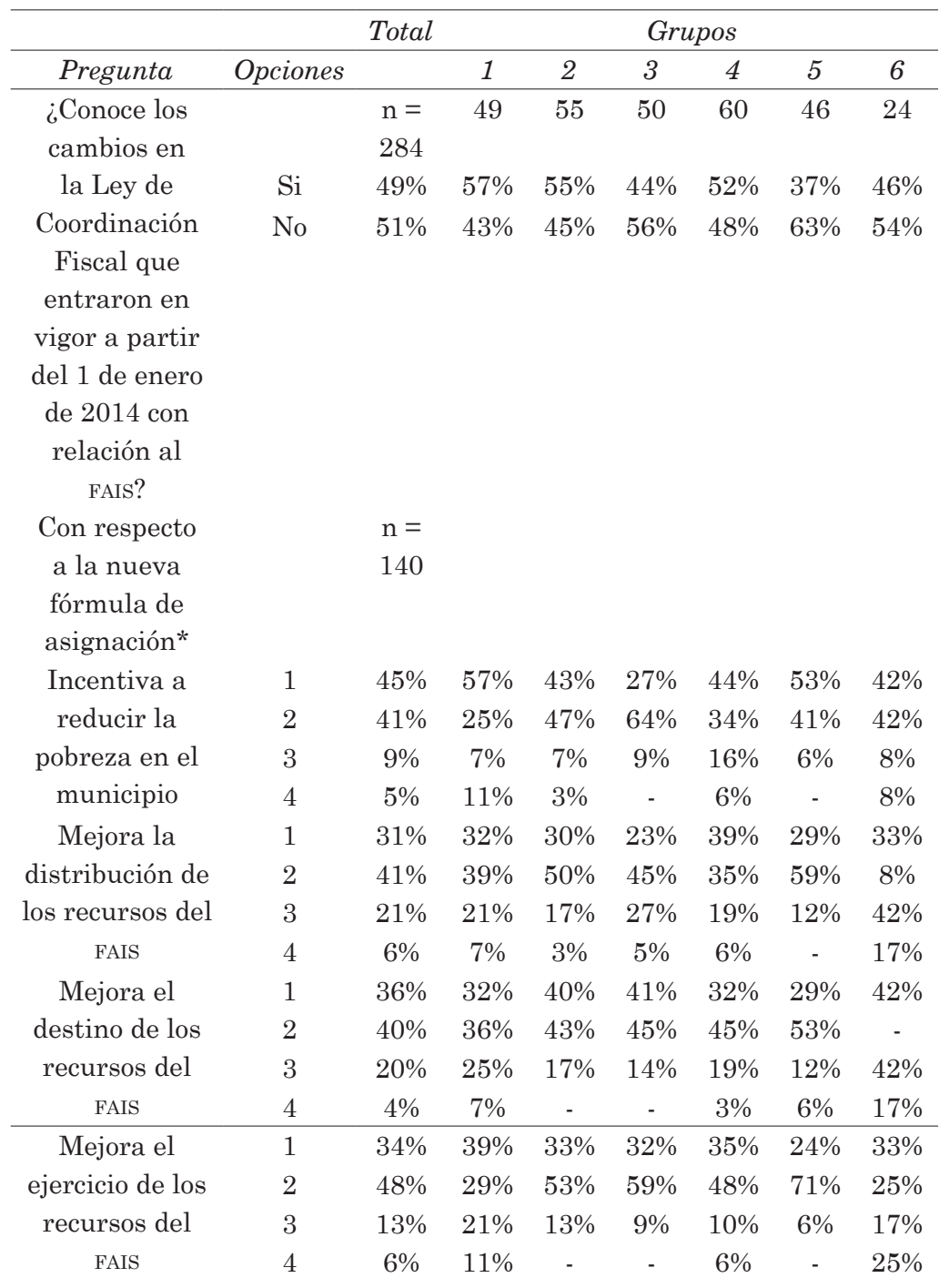

\section{8}


La percepción de los funcionarios municipales sobre la reforma de 2014 al Fondo de Aportaciones para la Infraestructura Social

\begin{tabular}{|c|c|c|c|c|c|c|c|c|}
\hline \multirow[b]{2}{*}{ Pregunta } & \multirow[b]{2}{*}{ Opciones } & \multicolumn{3}{|l|}{ Total } & \multicolumn{2}{|c|}{ Grupos } & & \multirow[b]{2}{*}{6} \\
\hline & & & 1 & 2 & 3 & 4 & & \\
\hline Refuerza los & 1 & $32 \%$ & $39 \%$ & $37 \%$ & $23 \%$ & $29 \%$ & $35 \%$ & $25 \%$ \\
\hline objetivos de & 2 & $51 \%$ & $39 \%$ & $53 \%$ & $64 \%$ & $58 \%$ & $47 \%$ & $33 \%$ \\
\hline creación del & 3 & $11 \%$ & $7 \%$ & $10 \%$ & $14 \%$ & $10 \%$ & $12 \%$ & $17 \%$ \\
\hline FAIS & 4 & $6 \%$ & $14 \%$ & - & - & $3 \%$ & $6 \%$ & $25 \%$ \\
\hline \multirow{2}{*}{$\begin{array}{l}\text { Asegura un } \\
\text { mejor uso de }\end{array}$} & 1 & $44 \%$ & $32 \%$ & $50 \%$ & $50 \%$ & $45 \%$ & $47 \%$ & $42 \%$ \\
\hline & 2 & $42 \%$ & $46 \%$ & $40 \%$ & $32 \%$ & $45 \%$ & $53 \%$ & $33 \%$ \\
\hline los recursos del & 3 & $9 \%$ & $14 \%$ & $7 \%$ & $18 \%$ & $6 \%$ & - & $8 \%$ \\
\hline FAIS & 4 & $4 \%$ & $7 \%$ & $3 \%$ & - & $3 \%$ & - & $17 \%$ \\
\hline Asegura & 1 & $45 \%$ & $43 \%$ & $47 \%$ & $59 \%$ & $42 \%$ & $47 \%$ & $25 \%$ \\
\hline una mayor & 2 & $39 \%$ & $32 \%$ & $43 \%$ & $27 \%$ & $35 \%$ & $53 \%$ & $50 \%$ \\
\hline transparencia & 3 & $12 \%$ & $18 \%$ & $10 \%$ & $14 \%$ & $16 \%$ & - & $8 \%$ \\
\hline & 4 & $4 \%$ & $7 \%$ & - & - & $6 \%$ & - & $17 \%$ \\
\hline \\
\hline \multicolumn{9}{|l|}{ las entidades } \\
\hline \multirow{2}{*}{\multicolumn{9}{|c|}{$\begin{array}{c}\text { federativas y } \\
\text { municipios. }\end{array}$}} \\
\hline & & & & & & & & \\
\hline Reducirá & 1 & $21 \%$ & $14 \%$ & $20 \%$ & $27 \%$ & $16 \%$ & $35 \%$ & $25 \%$ \\
\hline los recursos & 2 & $29 \%$ & $18 \%$ & $43 \%$ & $23 \%$ & $39 \%$ & $24 \%$ & $17 \%$ \\
\hline financieros a & 3 & $24 \%$ & $21 \%$ & $17 \%$ & $36 \%$ & $26 \%$ & $29 \%$ & $17 \%$ \\
\hline $\begin{array}{l}\text { los municipios } \\
\text { más pobres }\end{array}$ & 4 & $25 \%$ & $46 \%$ & $20 \%$ & $14 \%$ & $19 \%$ & $12 \%$ & $42 \%$ \\
\hline \multirow{2}{*}{$\begin{array}{c}\text { Establece con } \\
\text { claridad el }\end{array}$} & 1 & $37 \%$ & $36 \%$ & $37 \%$ & $50 \%$ & $29 \%$ & $41 \%$ & $33 \%$ \\
\hline & 2 & $48 \%$ & $43 \%$ & $43 \%$ & $41 \%$ & $61 \%$ & $59 \%$ & $33 \%$ \\
\hline destino de los & 3 & $12 \%$ & $18 \%$ & $20 \%$ & $5 \%$ & $10 \%$ & - & $17 \%$ \\
\hline $\begin{array}{l}\text { recursos del } \\
\text { fondo }\end{array}$ & 4 & $3 \%$ & $4 \%$ & - & $5 \%$ & - & - & $17 \%$ \\
\hline \multirow[t]{2}{*}{ Hace previsible } & 1 & $29 \%$ & $25 \%$ & $27 \%$ & $36 \%$ & $29 \%$ & $35 \%$ & $25 \%$ \\
\hline & 2 & $54 \%$ & $43 \%$ & $63 \%$ & $59 \%$ & $55 \%$ & $59 \%$ & $42 \%$ \\
\hline \multirow{3}{*}{$\begin{array}{l}\text { obtengan } \\
\text { mejores } \\
\text { resultados en } \\
\text { la aplicación de } \\
\text { los recursos }\end{array}$} & 3 & $14 \%$ & $29 \%$ & $10 \%$ & $5 \%$ & $16 \%$ & $6 \%$ & $8 \%$ \\
\hline & 4 & $3 \%$ & $4 \%$ & - & - & - & - & $25 \%$ \\
\hline & & & & & & & & \\
\hline \multirow{4}{*}{$\begin{array}{l}\text { Promueve la } \\
\text { eficiencia en el } \\
\text { ejercicio de los } \\
\text { recursos }\end{array}$} & 1 & $34 \%$ & $25 \%$ & $40 \%$ & $27 \%$ & $42 \%$ & $29 \%$ & $33 \%$ \\
\hline & 2 & $56 \%$ & $64 \%$ & $53 \%$ & $64 \%$ & $52 \%$ & $53 \%$ & $42 \%$ \\
\hline & 3 & $8 \%$ & $7 \%$ & $7 \%$ & $9 \%$ & $3 \%$ & $18 \%$ & $8 \%$ \\
\hline & 4 & $3 \%$ & $4 \%$ & - & - & $3 \%$ & - & $17 \%$ \\
\hline
\end{tabular}

Estado No.78-79 


\begin{tabular}{|c|c|c|c|c|c|c|c|c|}
\hline & & Total & & & Grt & & & \\
\hline Pregunta & Opciones & & 1 & 2 & 3 & 4 & 5 & 6 \\
\hline Es más claro & 1 & $22 \%$ & $18 \%$ & $20 \%$ & $32 \%$ & $19 \%$ & $24 \%$ & $25 \%$ \\
\hline el cálculo de & 2 & $46 \%$ & $43 \%$ & $50 \%$ & $50 \%$ & $45 \%$ & $41 \%$ & $42 \%$ \\
\hline la asignación & 3 & $26 \%$ & $29 \%$ & $27 \%$ & $14 \%$ & $29 \%$ & $35 \%$ & $25 \%$ \\
\hline $\begin{array}{c}\text { de fondos a los } \\
\text { estados }\end{array}$ & 4 & $6 \%$ & $11 \%$ & $3 \%$ & $5 \%$ & $6 \%$ & - & $8 \%$ \\
\hline Es más claro & 1 & $26 \%$ & $18 \%$ & $23 \%$ & $41 \%$ & $23 \%$ & $35 \%$ & $25 \%$ \\
\hline el cálculo de & 2 & $46 \%$ & $46 \%$ & $50 \%$ & $36 \%$ & $52 \%$ & $47 \%$ & $42 \%$ \\
\hline la asignación & 3 & $20 \%$ & $21 \%$ & $23 \%$ & $18 \%$ & $16 \%$ & $18 \%$ & $25 \%$ \\
\hline $\begin{array}{c}\text { de fondos a los } \\
\text { municipios }\end{array}$ & 4 & $7 \%$ & $14 \%$ & $3 \%$ & $5 \%$ & $10 \%$ & - & $8 \%$ \\
\hline La información & 1 & $32 \%$ & $29 \%$ & $23 \%$ & $36 \%$ & $26 \%$ & $47 \%$ & $50 \%$ \\
\hline usada es más & 2 & $51 \%$ & $50 \%$ & $60 \%$ & $36 \%$ & $65 \%$ & $41 \%$ & $42 \%$ \\
\hline opor & 3 & $12 \%$ & $11 \%$ & $17 \%$ & $23 \%$ & $6 \%$ & $12 \%$ & - \\
\hline & 4 & $4 \%$ & $11 \%$ & - & $5 \%$ & $3 \%$ & - & $8 \%$ \\
\hline Ha reducido el & 1 & $20 \%$ & $18 \%$ & $17 \%$ & $18 \%$ & $23 \%$ & $29 \%$ & $17 \%$ \\
\hline monto nominal & 2 & $34 \%$ & $32 \%$ & $27 \%$ & $45 \%$ & $39 \%$ & $41 \%$ & $17 \%$ \\
\hline que recibimos & 3 & $34 \%$ & $25 \%$ & $43 \%$ & $27 \%$ & $35 \%$ & $24 \%$ & $58 \%$ \\
\hline del Fondo & 4 & $11 \%$ & $25 \%$ & $13 \%$ & $9 \%$ & $3 \%$ & $6 \%$ & $8 \%$ \\
\hline Ha reducido el & 1 & $17 \%$ & $18 \%$ & $20 \%$ & $18 \%$ & $13 \%$ & $18 \%$ & $17 \%$ \\
\hline monto real que & 2 & $33 \%$ & $21 \%$ & $33 \%$ & $36 \%$ & $32 \%$ & $53 \%$ & $25 \%$ \\
\hline recibimos del & 3 & $36 \%$ & $36 \%$ & $37 \%$ & $36 \%$ & $39 \%$ & $24 \%$ & $42 \%$ \\
\hline Fondo & 4 & $14 \%$ & $25 \%$ & $10 \%$ & $9 \%$ & $16 \%$ & $6 \%$ & $17 \%$ \\
\hline $\begin{array}{l}\text { Con el nuevo } \\
\text { esquema para } \\
\text { operar el FAIS* }\end{array}$ & & $\begin{array}{l}\mathrm{n}= \\
140\end{array}$ & & & & & & \\
\hline La operación & 1 & $22 \%$ & $14 \%$ & $20 \%$ & $41 \%$ & $19 \%$ & $24 \%$ & $17 \%$ \\
\hline de los recursos & 2 & $32 \%$ & $21 \%$ & $33 \%$ & $27 \%$ & $29 \%$ & $53 \%$ & $42 \%$ \\
\hline es más sencilla & 3 & $28 \%$ & $36 \%$ & $30 \%$ & $9 \%$ & $35 \%$ & $18 \%$ & $33 \%$ \\
\hline & 4 & $18 \%$ & $29 \%$ & $17 \%$ & $23 \%$ & $16 \%$ & $6 \%$ & $8 \%$ \\
\hline Es más sencillo & 1 & $19 \%$ & $25 \%$ & $20 \%$ & $18 \%$ & $19 \%$ & $18 \%$ & $8 \%$ \\
\hline bajar los fondos & 2 & $41 \%$ & $46 \%$ & $40 \%$ & $45 \%$ & $35 \%$ & $29 \%$ & $50 \%$ \\
\hline federales & 3 & $28 \%$ & $25 \%$ & $27 \%$ & $14 \%$ & $32 \%$ & $41 \%$ & $33 \%$ \\
\hline & 4 & $12 \%$ & $4 \%$ & $13 \%$ & $23 \%$ & $13 \%$ & $12 \%$ & $8 \%$ \\
\hline La operación & 1 & $36 \%$ & $29 \%$ & $43 \%$ & $41 \%$ & $35 \%$ & $29 \%$ & $42 \%$ \\
\hline será más & 2 & $49 \%$ & $50 \%$ & $47 \%$ & $45 \%$ & $55 \%$ & $53 \%$ & $42 \%$ \\
\hline transparente & 3 & $9 \%$ & $11 \%$ & $7 \%$ & $5 \%$ & $6 \%$ & $18 \%$ & $8 \%$ \\
\hline & 4 & $6 \%$ & $11 \%$ & $3 \%$ & $9 \%$ & $3 \%$ & - & $8 \%$ \\
\hline
\end{tabular}


La percepción de los funcionarios municipales sobre la reforma de 2014 al Fondo de Aportaciones para la Infraestructura Social

\begin{tabular}{|c|c|c|c|c|c|c|c|c|}
\hline & & Total & & & Grt & pos & & \\
\hline Pregunta & Opciones & & 1 & 2 & 3 & 4 & 5 & 6 \\
\hline Los fondos & 1 & $39 \%$ & $21 \%$ & $40 \%$ & $41 \%$ & $55 \%$ & $41 \%$ & $33 \%$ \\
\hline deben & 2 & $44 \%$ & $43 \%$ & $50 \%$ & $45 \%$ & $35 \%$ & $47 \%$ & $42 \%$ \\
\hline estar mejor & 3 & $12 \%$ & $25 \%$ & $7 \%$ & $9 \%$ & $10 \%$ & $12 \%$ & $8 \%$ \\
\hline $\begin{array}{l}\text { focalizados } \\
\text { para la } \\
\text { reducción de la } \\
\text { pobreza en el } \\
\text { municipio }\end{array}$ & 4 & $5 \%$ & $11 \%$ & $3 \%$ & $5 \%$ & - & - & $17 \%$ \\
\hline Los fondos & 1 & $31 \%$ & $14 \%$ & $47 \%$ & $27 \%$ & $35 \%$ & $29 \%$ & $33 \%$ \\
\hline son más & 2 & $47 \%$ & $57 \%$ & $33 \%$ & $50 \%$ & $39 \%$ & $65 \%$ & $50 \%$ \\
\hline predecibles & 3 & $17 \%$ & $25 \%$ & $20 \%$ & $9 \%$ & $23 \%$ & $6 \%$ & $8 \%$ \\
\hline $\begin{array}{c}\text { y facilitan la } \\
\text { planeación } \\
\text { municipal }\end{array}$ & 4 & $4 \%$ & $4 \%$ & - & $14 \%$ & $3 \%$ & - & $8 \%$ \\
\hline Se ha & 1 & $27 \%$ & $18 \%$ & $30 \%$ & $27 \%$ & $29 \%$ & $35 \%$ & $25 \%$ \\
\hline beneficiado a & 2 & $38 \%$ & $54 \%$ & $33 \%$ & $36 \%$ & $29 \%$ & $41 \%$ & $33 \%$ \\
\hline los municipios & 3 & $26 \%$ & $21 \%$ & $27 \%$ & $23 \%$ & $29 \%$ & $24 \%$ & $33 \%$ \\
\hline más pobres & 4 & $9 \%$ & $7 \%$ & $10 \%$ & $14 \%$ & $13 \%$ & - & $8 \%$ \\
\hline Se han & 1 & $25 \%$ & $39 \%$ & $30 \%$ & $27 \%$ & $23 \%$ & $12 \%$ & - \\
\hline generado & 2 & $47 \%$ & $36 \%$ & $40 \%$ & $55 \%$ & $52 \%$ & $41 \%$ & $75 \%$ \\
\hline obstáculos y & 3 & $21 \%$ & $18 \%$ & $23 \%$ & $18 \%$ & $19 \%$ & $41 \%$ & $8 \%$ \\
\hline $\begin{array}{l}\text { barreras en los } \\
\text { municipios más } \\
\text { desarrollados }\end{array}$ & 4 & $6 \%$ & $7 \%$ & $7 \%$ & - & $6 \%$ & $6 \%$ & $17 \%$ \\
\hline Se han & 1 & $19 \%$ & $18 \%$ & $27 \%$ & $5 \%$ & $23 \%$ & $18 \%$ & $17 \%$ \\
\hline generado & 2 & $36 \%$ & $21 \%$ & $30 \%$ & $45 \%$ & $35 \%$ & $47 \%$ & $58 \%$ \\
\hline obstáculos y & 3 & $32 \%$ & $50 \%$ & $30 \%$ & $36 \%$ & $29 \%$ & $24 \%$ & $8 \%$ \\
\hline $\begin{array}{c}\text { barreras en los } \\
\text { municipios más } \\
\text { pobres }\end{array}$ & 4 & $13 \%$ & $11 \%$ & $13 \%$ & $14 \%$ & $13 \%$ & $12 \%$ & $17 \%$ \\
\hline Se han & 1 & $21 \%$ & $21 \%$ & $33 \%$ & $9 \%$ & $23 \%$ & $12 \%$ & $17 \%$ \\
\hline generado & 2 & $34 \%$ & $25 \%$ & $27 \%$ & $41 \%$ & $32 \%$ & $47 \%$ & $42 \%$ \\
\hline obstáculos y & 3 & $34 \%$ & $39 \%$ & $30 \%$ & $36 \%$ & $32 \%$ & $29 \%$ & $33 \%$ \\
\hline $\begin{array}{c}\text { barreras en } \\
\text { los municipios } \\
\text { rurales }\end{array}$ & 4 & $12 \%$ & $14 \%$ & $10 \%$ & $14 \%$ & $13 \%$ & $12 \%$ & $8 \%$ \\
\hline
\end{tabular}

Estado No.78-79 


\begin{tabular}{ccccccccc}
\hline & \multicolumn{3}{c}{ Total } & \multicolumn{7}{c}{ Grupos } \\
\hline Pregunta & Opciones & & 1 & 2 & 3 & 4 & 5 & 6 \\
\hline Se han & 1 & $22 \%$ & $29 \%$ & $27 \%$ & $23 \%$ & $23 \%$ & $12 \%$ & $8 \%$ \\
generado & 2 & $41 \%$ & $39 \%$ & $40 \%$ & $32 \%$ & $45 \%$ & $53 \%$ & $42 \%$ \\
obstáculos y & 3 & $29 \%$ & $21 \%$ & $27 \%$ & $41 \%$ & $26 \%$ & $29 \%$ & $33 \%$ \\
barreras en & 4 & $8 \%$ & $11 \%$ & $7 \%$ & $5 \%$ & $6 \%$ & $6 \%$ & $17 \%$ \\
los municipios & & & & & & & & \\
urbanos & & & & & & & & \\
\hline
\end{tabular}

Notas. La integración de los grupos de municipios se muestra en el cuadro 1. * En cada aseveración $1=$ completamente de acuerdo, $2=$ de acuerdo, 3 = desacuerdo y $4=$ completamente en desacuerdo

Fuente: Construcción propia sobre la base de los resultados del cuestionario a municipios.

Cuadro 3. Estadísticos de prueba para proporciones de respuesta

\begin{tabular}{|c|c|c|c|c|}
\hline \multirow{2}{*}{\multicolumn{2}{|c|}{$\begin{array}{c} \\
\text { ¿Conoce los cambios en la Ley de } \\
\text { Coordinación Fiscal que entraron en } \\
\text { vigor a partir del } 1 \text { de enero de } 2014 \\
\text { con relación al FAIs? }\end{array}$}} & \multirow{2}{*}{$\begin{array}{c}\text { Valor } \\
\text { estimado } \\
(p) \\
49 \%\end{array}$} & \multirow{2}{*}{$\begin{array}{c}\text { Estadistico } \\
\text { de prueba } \\
(z) \\
-0.34\end{array}$} & \multirow{2}{*}{$\begin{array}{c}p \text {-valor } \\
0.3669\end{array}$} \\
\hline & & & & \\
\hline z & $\begin{array}{c}\text { Incentiva a reducir la pobreza en el } \\
\text { municipio (hipótesis 1) }\end{array}$ & $86 \%$ & 8.55 & 0.0000 \\
\hline 岸 & $\begin{array}{c}\text { Mejora la distribución de los } \\
\text { recursos del FAIS }\end{array}$ & $72 \%$ & 5.21 & 0.0000 \\
\hline$\frac{\sqrt{6}}{\sqrt{2}}$ & $\begin{array}{c}\text { Mejora el destino de los recursos } \\
\text { del FAIS }\end{array}$ & $76 \%$ & 6.15 & 0.0000 \\
\hline 琶 & $\begin{array}{c}\text { Mejora el ejercicio de los recursos } \\
\text { del FAIs (hipótesis 4) }\end{array}$ & $82 \%$ & 7.57 & 0.0000 \\
\hline 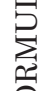 & $\begin{array}{c}\text { Refuerza los objetivos de creación } \\
\text { del FAIS }\end{array}$ & $83 \%$ & 7.81 & 0.0000 \\
\hline 怘 & $\begin{array}{l}\text { Asegura un mejor uso de los } \\
\text { recursos del FAIS }\end{array}$ & $86 \%$ & 8.52 & 0.0000 \\
\hline $\begin{array}{l}\text { 毡 } \\
\text { 岁 }\end{array}$ & $\begin{array}{l}\text { Asegura una mayor transparencia } \\
\text { en la distribución de los recursos } \\
\text { a las entidades federativas y } \\
\text { municipios (hipótesis 4) }\end{array}$ & $84 \%$ & 8.05 & 0.0000 \\
\hline
\end{tabular}


La percepción de los funcionarios municipales sobre la reforma de 2014 al Fondo de Aportaciones para la Infraestructura Social

\begin{tabular}{|c|c|c|c|c|}
\hline & & $\begin{array}{l}\text { Valor } \\
\text { estimado } \\
(p)\end{array}$ & $\begin{array}{l}\text { Estadístico } \\
\text { de prueba } \\
(z)\end{array}$ & p-valor \\
\hline \multirow{9}{*}{ 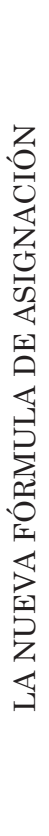 } & $\begin{array}{c}\text { Reducirá los recursos financieros a } \\
\text { los municipios más pobres }\end{array}$ & $50 \%$ & 0 & 0.3989 \\
\hline & $\begin{array}{l}\text { Establece con claridad el destino de } \\
\text { los recursos del fondo (hipótesis } 4 \text { ) }\end{array}$ & $85 \%$ & 8.28 & 0.0000 \\
\hline & $\begin{array}{l}\text { Hace previsible que se obtengan } \\
\text { mejores resultados en la aplicación } \\
\text { de los recursos }\end{array}$ & $83 \%$ & 7.81 & 0.0000 \\
\hline & $\begin{array}{c}\text { Promueve la eficiencia en el } \\
\text { ejercicio de los recursos (hipótesis 4) }\end{array}$ & $90 \%$ & 9.47 & 0.0000 \\
\hline & $\begin{array}{l}\text { Es más claro el cálculo de la } \\
\text { asignación de fondos a los estados }\end{array}$ & $68 \%$ & 4.26 & 0.0000 \\
\hline & $\begin{array}{c}\text { Es más claro el cálculo de la } \\
\text { asignación de fondos a los } \\
\text { municipios }\end{array}$ & $72 \%$ & 5.21 & 0.0000 \\
\hline & $\begin{array}{c}\text { La información usada es más } \\
\text { oportuna (hipótesis 2) }\end{array}$ & $83 \%$ & 7.81 & 0.0000 \\
\hline & $\begin{array}{l}\text { Ha reducido el monto nominal que } \\
\text { recibimos del Fondo }\end{array}$ & $54 \%$ & 0.95 & 0.2541 \\
\hline & $\begin{array}{l}\text { Ha reducido el monto real que } \\
\text { recibimos del Fondo }\end{array}$ & $50 \%$ & 0 & 0.3989 \\
\hline
\end{tabular}




\begin{tabular}{|c|c|c|c|c|}
\hline & & $\begin{array}{l}\text { Valor } \\
\text { estimado } \\
\quad(p)\end{array}$ & $\begin{array}{l}\text { Estadístico } \\
\text { de prueba } \\
\text { (z) }\end{array}$ & $p$-valor \\
\hline & $\begin{array}{l}\text { La operación de los recursos es más } \\
\text { sencilla }\end{array}$ & $54 \%$ & 0.95 & 0.2541 \\
\hline$\sum_{1}^{\infty 2}$ & $\begin{array}{c}\text { Es más sencillo bajar los fondos } \\
\text { federales }\end{array}$ & $60 \%$ & 2.37 & 0.0241 \\
\hline 国 & La operación será más transparente & $85 \%$ & 8.28 & 0.0000 \\
\hline $\begin{array}{l}\sum_{12}^{2} \\
\frac{1}{c} \\
\frac{1}{0} \\
0\end{array}$ & $\begin{array}{c}\text { Los fondos deben estar mejor } \\
\text { focalizados para la reducción de la } \\
\text { pobreza en el municipio (hipótesis 3) }\end{array}$ & $83 \%$ & 7.81 & 0.0000 \\
\hline 應 & $\begin{array}{l}\text { Los fondos son más predecibles y } \\
\text { facilitan la planeación municipal }\end{array}$ & $78 \%$ & 6.63 & 0.0000 \\
\hline$\sum_{x}^{\zeta}$ & $\begin{array}{l}\text { Se ha beneficiado a los municipios } \\
\text { más pobres }\end{array}$ & $65 \%$ & 3.55 & 0.0007 \\
\hline 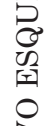 & $\begin{array}{c}\text { Se han generado obstáculos y } \\
\text { barreras en los municipios más } \\
\text { desarrollados }\end{array}$ & $72 \%$ & 5.21 & 0.0000 \\
\hline 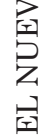 & $\begin{array}{c}\text { Se han generado obstáculos y } \\
\text { barreras en los municipios más } \\
\text { pobres }\end{array}$ & $55 \%$ & 1.18 & 0.1989 \\
\hline Zু & $\begin{array}{c}\text { Se han generado obstáculos y } \\
\text { barreras en los municipios rurales }\end{array}$ & $55 \%$ & 1.18 & 0.1989 \\
\hline & $\begin{array}{c}\text { Se han generado obstáculos y } \\
\text { barreras en los municipios urbanos }\end{array}$ & $63 \%$ & 3.08 & 0.0035 \\
\hline
\end{tabular}
$\begin{aligned} & \text { Nota: El estadístico de prueba se calculó como: } \\ & \text { Fuente: Construcción propia sobre la base de los }\end{aligned} \mathrm{z}=\frac{\mathrm{p}-\mathrm{P}}{\sqrt{\mathrm{P}(1-\mathrm{P}) / \mathrm{n}}}$ resultados del Cuestionario a Municipios.

\section{Conclusiones}

En este artículo se han presentado los resultados de una encuesta aplicada a una muestra de funcionarios municipales sobre la Reforma en la LCF de 2014 con respecto al FAIS. Hasta donde tenemos conocimiento, este es el primer esfuerzo sistemático por conocer la percepción de los municipios con respecto a esta reforma, justo después de que estuvo operando por un año. 
La percepción de los funcionarios municipales sobre la reforma de 2014 al Fondo de Aportaciones para la Infraestructura Social

Después de quince años de asignarse recursos federales a los estados y los municipios para, conjuntamente con el gobierno federal, implementar la política social a través de la inversión en infraestructura social, las reglas del FAIS fueron modificadas. Esta es la segunda reforma mayor en el esquema de transferencias condicionadas para reducir la pobreza. La primera fue cuando se instituyó el FAIs en 1998.

No solo la aprobación de la reforma, sino también la percepción un año después de estar operando, pueden ser, en nuestra opinión, señales de una buena labor política conjunta de la SHCP y la SEDESOL, y de un buen diagnóstico de la SEDESOL en cuanto a la problemática del FAIS. Ni los representantes políticos que aprobaron la iniciativa, ni los funcionarios municipales que la operan, muestran objeciones mayores, a pesar de que los cambios en las reglas para asignar recursos puedan implicar variaciones en los recursos asignados a las tesorerías municipales.

En particular, en este artículo postulamos cuatro hipótesis fundamentales, que fueron confirmadas por los resultados. Hay evidencia clara de que la mayoría de los funcionarios municipales considera que la nueva fórmula del FAIs incentiva a reducir la pobreza, que la información que se usa en la fórmula es más oportuna, que con el nuevo esquema para operar el FAIs los recursos estarán mejor focalizados y que se mejorarán la transparencia, el destino y el ejercicio de los recursos.

En efecto, los resultados de este estudio nos muestran que la mayoría de los funcionarios municipales está de acuerdo con casi la totalidad de las características del FAIs, tal como se especifican en la nueva LCF. Quizás lo único que deberíamos anotar al respecto es que el 38\% no consideró adecuado que la fórmula nueva garantice el monto nominal de 2013. Los municipios en los extremos del espectro de ingreso municipal per capita ( 1 y 6 ) muestran los mayores porcentajes de respuesta en este asunto. Relacionado con 
esto, poco más de la mitad de los funcionarios municipales dijo haber experimentado una reducción en la asignación de recursos vía el FAIs.

Así, no parece haber algún aspecto en la definición de reglas y operación del FAIs que deba reconsiderarse: Integración, cómo se entera, destino, transparencia y fórmula de asignación. Estos resultados revisten especial importancia, ya que, a un año de estar operando las nuevas reglas del FAIS, los funcionarios encargados de su implementación que efectivamente conocen de la reforma perciben que se cumplirán los objetivos para los que fueron diseñadas. De esta forma, los resultados parecen indicar que existe una percepción positiva con relación a la reforma del FAIS.

En función del conocimiento de los cambios, estas respuestas, sin embargo, pueden tener una parcial validez. Después de un año de que la reforma había entrado en vigor, más de la mitad de los funcionarios entrevistados no la conocían. Si bien es cierto que la labor política y el diagnóstico pudieron ser acertados por parte de la SEDESOL para lograr la aprobación de la reforma, queda pendiente el interés de las administraciones municipales, conjuntamente con la labor de difusión por parte de la SEDESOL, para que los encargados de las áreas sustantivas en los municipios tengan conocimiento de las nuevas reglas del FAIs.

Lo que queda como preocupación, en función de las respuestas de quienes dijeron conocer la reforma del FAIS, es la expectativa de que con la nueva fórmula se reducirán los recursos a los municipios más pobres y la consideración sobre una operación más complicada del Fondo. Esto último se suma a la percepción de que se han generado obstáculos y barreras en los municipios, independientemente de su nivel de desarrollo.

La operación más complicada y la percepción de obstáculos y barreras estarían en línea directa con la mayor transparencia y focalización de los recursos para reducir 
efectivamente la pobreza. Estas complicaciones y obstáculos habrán de ser una necesidad en aras de la transparencia y la focalización, que, por cierto, es bien vista por los funcionarios municipales.

Más allá de la percepción que puedan tener quienes operan e implementan a escala municipal las reglas para la aplicación de los recursos asociados al FAIs, parecería difícil pensar que, en efecto, la información que será usada en la fórmula de asignación es oportuna. Hasta el año 2013 se emplearon principalmente datos de los censos de población, que se actualizaban cada diez años. Ahora se utilizan los datos de pobreza multidimensional, que a escala municipal serán actualizados cada cinco años. Es posible, entonces, que una administración municipal no experimente ningún cambio en las variables empleadas en la fórmula de asignación, a pesar de haber realizado esfuerzos para mejorar la situación de pobreza del municipio. Si bien, al menos en el diseño, la nueva fórmula de asignación premia parcialmente la reducción de pobreza a escala municipal, los esfuerzos municipales en este sentido pueden no responder al incentivo deseado, si la administración no tiene la visión para trabajar en favor del municipio que administra, en lugar de perseguir fines meramente políticos.

Anderson, J.y J. Gerber (2008). Fifthy Years of Change on the Bibliografía

U.S. - Mexico Border. Growth, Development and Quality of Life. Austin: University of Texas Press.

Arellano Ríos, A.; Flores Ascencio, S. y R. Piedra Ascencio (2019). "Valoración del Fondo de Aportaciones para la Infraestructura Social, en San Pedro Tlaquepaque, Jalisco". Región y Sociedad, 3 I. Disponible en: https://doi. org/l0.22I98/rys2019/3 I/I037.

Barceinas, C.y R. Monroy (2002). Origen y funcionamiento del Ramo 33. Disponible en: https://ferrusca.files.wordpress. com/2013/03/analisis_sintetico_ramo33.pdf. 
Cámara de Diputados del H. Congreso de la Unión (20I3). Decreto por el que se reforman, adicionan y derogan diversas disposiciones de la Ley de Coordinación Fiscal. Disponible en: http://www.diputados.gob.mx/sedia/biblio/ prog_leg/I0l_Dof_09dicl3.pdf.

CEFP (2005). Diagnóstico del Fondo de Aportaciones para la Infraestructura Social Municipal. Disponible en: http:// www.cefp.gob.mx/notas/notacefp0 I02005.pdf.

(2007). Impacto del Fals sobre el índice de marginación, 2000-2005. Disponible en: http://www.cefp.gob.mx/ notas/2007/notacefp0302007.pdf.

(2009). Diagnóstico del Fondo de Aportaciones para la Infraestructura Social Municipal. Disponible en: http:// www.cefp.gob.mx/intr/edocumentos/pdf/cefp/2009/ cefp0342009.pdf.

Cejudo, G. y R. Gerhard (2009). La rendición de cuentas de transferencias intergubernamentales: El caso del FAIs. Documento de trabajo núm. 223 CIDE.

CEPAL (2004). Descentralización a escala municipal en México: La inversión en infraestructura social. México: CEPAL. Chiapa, C.y C.Velázquez (Coord.) (20I I). Estudios del Ramo 33. México: El Colegio de México y Consejo Nacional de Evaluación de la Política de Desarrollo Social. CIDAC (2003). Los retos del federalismo mexicano: La cuestión de la efectividad del gasto descentralizado y la rendición de cuentas. México: Fundación Friedrich Naumann y CIDAC. CONEVAL (20I I). El Ramo 33 en el desarrollo social en México: Evaluación de ocho fondos de política pública. México: Consejo Nacional de Evaluación de la Política de Desarrollo Social.

Díaz Cayeros, A. y S. Silva (2004). Descentralización a escala municipal en México: La inversión en infraestructura social. México: CEPAL.

Fleming, M. y J. Nellis (2000). Principles of Applied Statistics. London:Thomson. 
Hernández Trillo, F.y B. Jarillo Rabling (2007).“Transferencias condicionadas federales en países en desarrollo: El caso del FISM en México". Estudios Económicos, 22(2), I 43-I84. Disponible en: https://estudioseconomicos.colmex.mx/ archivo/EstudiosEconomicos 2007//43-184.pdf.

Ibarra Salazar, J. (20I8). “Fundamentos de la nueva fórmula de asignación del Fondo de Aportaciones para la Infraestructura Social en México”. Trimestre Económico, 8 5(I), 195-2 I8. Disponible en: http://dx.doi.org/ | 0.20430/ete. v85i337.664.

Ibarra Salazar, J. y A. Mollick (2006). "Mexican Northern Border Municipalities, Financial Dependence and Institutions". Annals of Regional Science, 40 (4), 859-874. Disponible en: https://doi.org// 0.1007/s00 168-0050036-4.

INAFED (20I I). Manual de transferencias federales para municipios. México: INAFED.

Michel, H. (2003). "México: Evaluación del sistema de federalismo fiscal y escenarios futuros seleccionados". En INDETEC-ICMA-USAID-DEVETECH. Enfoques alternativos del federalismo fiscal en México. México.

Moreno, C. (2007). "Gasto público y elecciones: Una explicación política de la asignación de los presupuestos municipales en México”. Foro Internacional, 42 (2), 408434. Disponible en: file:///C:/Users/L0024 I2 I6/Downloads/I846-I836-I-PB.pdf.

PNUD (20I4). Índice de desarrollo humano municipal en México: Nueva metodología. Disponible en: http://www.mx.undp. org/content/dam/mexico/docs/Publicaciones/ PublicacionesReduccionPobreza/InformesDesarrolloHumano/ UNDP-MX-PovRed-IDHmunicipalMexico-0320 I4.pdf. Ramones, F. y D. Prudencio (20I4). "Los efectos del Fondo de Aportaciones para la Infraestructura Social sobre la pobreza en México". Región y Sociedad, 26 (60), 63-88. Disponible en: https://doi.org/10.22198/rys.2014.60.a9. 
Ruíz Porras,A.y N. García Vázquez (200 I4).“El federalismo fiscal y las transferencias planeadas hacia los municipios mexicanos: criterios económicos y políticos". Espiral 21 (59), 69-86. Disponible en: http://dx.doi.org// 0.32870/ espiral.v2 I i59.3 I8.g358.

Sánchez,A. (2000). Marginación e ingreso en los municipios de México. México: UnAM y Miguel Ángel Porrúa.

SHCP (20I0). Resumen ejecutivo de la consultoría para realizar evaluaciones del Ramo 33. México: INAP y BID.

Sour, L.y J. Ortega (2008). Marco institucional formal del Fals y del FAFM en México. Documento de trabajo núm. 210 CIDE.

Székely, M.; López, L.; Meléndez,A.; Rascón, E.y L. Rodríguez (2007). "Poniendo a la pobreza de ingresos y a la desigualdad en el mapa de México". Economía Mexicana, nueva época, 16 (2), 239-303. Disponible en: http:// www.economiamexicana.cide.edu/num_anteriores/ XVI-2/03_SZEKELY.pdf.

Torre, R. de la (2005). El Índice de Desarrollo Humano y la asignación del gasto público por entidad federativa en México. México: Universidad Iberoamericana.

Unikel, L.; Ruiz, C. y G. Garza (1976). El desarrollo urbano de México: Diagnóstico e implicaciones futuras. México: El Colegio de México.

Vázquez Elorza, A. y Reyes Munguía A. (20I6). Política pública en materia de desarrollo social mediante el Fondo de Infraestructura Social Municipal Potosino. EconoQuantum, I3 (I), 29-49. Disponible en: https://doi. org/l0.1838I/eq.v|3il.4870.

Wellenstein, A.; Núñez, A. y L. Andrés (2006). “Social Infrastructure: Fondo de aportaciones para la infraestructura social (FAIS)". En The World Bank. Decentralized Service Delivery for the Poor. Washington DC. 
La percepción de los funcionarios municipales sobre la reforma de 2014 al Fondo de Aportaciones para la Infraestructura Social

Anexo. Cuestionario a funcionarios municipales

Mejoras en el uso y aplicación de los recursos asignados vía el Fondo de

Aportaciones para la Infraestructura Social Municipal

\section{.Cuestionario}

\section{Sección I. Sobre las características del FAIS}

1. A continuación se van a presentar un conjunto de preguntas, del FAIs, le pido de favor indique sí está o no de acuerdo con cada una de ellas y si cuenta con algún comentario al respecto

\begin{tabular}{|c|c|c|}
\hline \multicolumn{3}{|l|}{ Característica } \\
\hline \multicolumn{3}{|l|}{ Integración } \\
\hline \multirow{2}{*}{$\begin{array}{l}\text { 1. ¿Considera adecuado que el FAIs se integre con } \\
\text { un } 2.5294 \% \text { de la recaudación federal participable? }\end{array}$} & A) Sí & ¿Por qué? \\
\hline & B) No & \\
\hline \multirow{4}{*}{$\begin{array}{c}2 . \text { ¿Considera adecuado que el } 0.3066 \% \text { y el } \\
2.2228 \% \text { de la recaudación federal participable } \\
\text { se asigne a las entidades y municipios } \\
\text { respectivamente? }\end{array}$} & A) Sí & ¿Por qué? \\
\hline & B) No & \\
\hline & & \\
\hline & & \\
\hline \multicolumn{2}{|l|}{ Cómo se entera } & ¿Por qué? \\
\hline \multirow{2}{*}{$\begin{array}{c}\text { 3. ¿Considera adecuado que el FAIs se entere } \\
\text { mensualmente en los primeros } 10 \text { meses del año? }\end{array}$} & A) Sí & ¿Por qué? \\
\hline & B) No & \\
\hline \multirow{2}{*}{$\begin{array}{l}\text { 4. ¿Considera adecuado que se entere } \\
\text { mensualmente en partes iguales? }\end{array}$} & A) Sí & ¿Por qué? \\
\hline & B) No & \\
\hline \multirow{2}{*}{$\begin{array}{c}\text { 5. ¿Considera adecuado que se entere a los } \\
\text { municipios a través de las entidades federativas? }\end{array}$} & A) Sí & ¿Por qué? \\
\hline & B) No & \\
\hline Destino & & ¿Por qué? \\
\hline \multirow{6}{*}{$\begin{array}{l}\text { 6. ¿Considera adecuado que el FAIs se destine } \\
\text { exclusivamente a financiar obras, acciones sociales } \\
\text { básicas e inversiones que beneficien directamente } \\
\text { a población en pobreza extrema, localidades con } \\
\text { alto o muy alto nivel de rezago social y a zonas de } \\
\text { atención prioritaria? }\end{array}$} & A) Sí & ¿Por qué? \\
\hline & B) $\mathrm{No}$ & \\
\hline & & \\
\hline & & \\
\hline & & \\
\hline & & \\
\hline
\end{tabular}




\begin{tabular}{|c|c|c|}
\hline $\begin{array}{l}\text { 7. ¿Considera adecuado que los recursos del FAIS se } \\
\text { destinen a proyectos de agua potable? }\end{array}$ & $\begin{array}{l}\text { A) Sí } \\
\text { B) No }\end{array}$ & ¿Por qué? \\
\hline $\begin{array}{l}\text { 8. ¿Considera adecuado que los recursos del faIs se } \\
\text { destinen a proyectos de alcantarillado? }\end{array}$ & $\begin{array}{l}\text { A) Sí } \\
\text { B) No }\end{array}$ & ¿Por qué? \\
\hline $\begin{array}{l}\text { 9. ¿Considera adecuado que los recursos del FAIS se } \\
\text { destinen a proyectos de drenaje y letrinas? }\end{array}$ & $\begin{array}{l}\text { A) Sí } \\
\text { B) No }\end{array}$ & ¿Por qué? \\
\hline $\begin{array}{l}\text { 10. ¿Considera adecuado que los recursos del FAIS } \\
\text { se destinen a proyectos de urbanización? }\end{array}$ & $\begin{array}{l}\text { A) Sí } \\
\text { B) No }\end{array}$ & ¿Por qué? \\
\hline $\begin{array}{l}\text { 11. ¿Considera adecuado que los recursos del FAIs } \\
\text { se destinen a proyectos de electrificación rural? }\end{array}$ & $\begin{array}{l}\text { A) Sí } \\
\text { B) No }\end{array}$ & ¿Por qué? \\
\hline $\begin{array}{l}\text { 12. ¿Considera adecuado que los recursos del } \\
\text { FAIs se destinen a proyectos de electrificación de } \\
\text { colonias pobres? }\end{array}$ & $\begin{array}{l}\text { A) Sí } \\
\text { B) No }\end{array}$ & ¿Por qué? \\
\hline $\begin{array}{l}\text { 13. ¿Considera adecuado que los recursos del } \\
\text { FAIs se destinen a proyectos de mejoramiento de } \\
\text { vivienda? }\end{array}$ & $\begin{array}{l}\text { A) Sí } \\
\text { B) No }\end{array}$ & ¿Por qué? \\
\hline $\begin{array}{c}\text { 14. ¿Considera adecuado que los recursos del FAIs } \\
\text { se destinen a proyectos de mantenimiento de } \\
\text { infraestructura? }\end{array}$ & $\begin{array}{l}\text { A) Sí } \\
\text { B) No }\end{array}$ & ¿Por qué? \\
\hline $\begin{array}{l}\text { 15. ¿Considera adecuado que las obras y acciones } \\
\text { que se realicen con los recursos del FAIs se orienten } \\
\text { conforme al Informe anual de la situación de } \\
\text { pobreza y rezago social que realice la sEDESOL? }\end{array}$ & $\begin{array}{l}\text { A) Sí } \\
\text { B) No }\end{array}$ & ¿Por qué? \\
\hline $\begin{array}{c}\text { 16. ¿Considera adecuado que los municipios } \\
\text { dispongan de hasta un } 2 \% \text { del total de recursos } \\
\text { del FAIsM que les correspondan para realizar } \\
\text { un programa de desarrollo institucional } \\
\text { (fortalecimiento de capacidades de gestión del } \\
\text { municipio)? }\end{array}$ & $\begin{array}{l}\text { A) Sí } \\
\text { B) No }\end{array}$ & ¿Por qué? \\
\hline $\begin{array}{c}\text { 17. ¿Considera adecuado que los municipios } \\
\text { destinen hasta el } 3 \% \text { del total de recursos del } \\
\text { FAISM para aplicarlos como gastos indirectos en } \\
\text { la verificación y seguimiento de las obras, en } \\
\text { la realización de estudios y la evaluación de } \\
\text { proyectos? }\end{array}$ & $\begin{array}{l}\text { A) Sí } \\
\text { B) No }\end{array}$ & ¿Por qué? \\
\hline \multicolumn{3}{|l|}{ Transparencia } \\
\hline $\begin{array}{c}\text { 18. ¿Considera adecuado que la SEDESOL debe } \\
\text { publique el informe anual sobre la situación de } \\
\text { pobreza y rezago social? }\end{array}$ & $\begin{array}{l}\text { A) Sí } \\
\text { B) No }\end{array}$ & ¿Por qué? \\
\hline
\end{tabular}


19. ¿Considera adecuado que la SEDESOL capacite sobre el funcionamiento del FAIS y del Programa de Desarrollo Institucional Municipal?

20. ¿Considera adecuado que los municipios deban hacer del conocimiento de sus habitantes los montos que reciban, las obras y acciones a realizar, el costo de cada una, su ubicación, metas y beneficiarios?

21. ¿Considera adecuado que los municipios deban promover la participación de las comunidades beneficiarias en su destino, aplicación y vigilancia, así como en la programación, ejecución, control, seguimiento y evaluación de las obras y acciones que se vayan a realizar?

22. ¿Considera adecuado que los municipios deban informar a sus habitantes los avances del ejercicio de los recursos trimestralmente y al término de cada ejercicio, sobre los resultados alcanzados?

23. ¿Considera adecuado proporcionar a la SEDESOL la información que sobre la utilización del FAIs le A) Sí ¿Por qué? sea requerida por conducto de las entidades?

24. ¿Considera adecuado procurar que las obras que realicen con los recursos del faIs sean compatibles con la preservación y protección del medio ambiente y que impulsen el desarrollo sostenible?

\begin{tabular}{cll}
\hline 25. ¿Considera adecuado reportar trimestralmente & A) Sí & ¿Por qué? \\
a la SEDESOL, a través de sus delegaciones & B) No &
\end{tabular}
estatales, así como a la SHCP, el seguimiento sobre el uso de los recursos del fais?

26. ¿Considera adecuado publicar en su página oficial de Internet las obras financiadas con los
A) Sí ¿Por qué?
B) $\mathrm{No}$
A) Sí ¿Por qué?
B) $\mathrm{No}$
A) Sí ¿Por qué?
B) $\mathrm{No}$

A) Sí ¿Por qué?
B) No
recursos del FAIS?

\begin{tabular}{clc}
\hline La fórmula de asignación & & \\
\hline $\begin{array}{c}\text { 27. ¿Considera adecuado que la fórmula garantice } \\
\text { el monto nominal de } 2013 ?\end{array}$ & $\begin{array}{l}\text { A) Sí } \\
\text { BPor qué? No }\end{array}$ & \\
\hline $\begin{array}{c}\text { 28. ¿Considera adecuado que el incremento } \\
\text { nominal del fais se distribuya con el número de }\end{array}$ & B) Nó & ¿Por qué? \\
carencias de la población y con la eficacia en la & & \\
reducción de la pobreza? & \\
\hline
\end{tabular}


29. ¿Considera adecuado que se asigna el 80\% del incremento nominal del faIs de acuerdo con el número de carencias de la población?

30. ¿Considera adecuado que se asigne el $20 \%$ del incremento nominal del FAIs de acuerdo con la eficacia en la reducción de la pobreza?

31. ¿Considera adecuado que el 15 de agosto de cada año la SEDESOL publique en el DOF las variables y fuentes de información para el cálculo de la fórmula y dé a conocer los porcentajes de participación que se asignarán a cada entidad?

32. ¿Considera adecuado que las entidades distribuyan entre los municipios el FAISM con una fórmula igual a la empleada a escala nacional, utilizando la información de pobreza extrema más reciente a nivel municipal?

33. ¿Considera adecuado que las entidades calculen y publiquen a más tardar el 31 de enero del ejercicio fiscal que corresponda, la distribución del FAISM entre sus municipios?

34. ¿Considera adecuado que las entidades entreguen a sus municipios los recursos conforme al calendario de enteros con que la Federación lo haga a ellas?
A) Sí ¿Por qué?
B) $\mathrm{No}$

A) Sí ¿Por qué?

B) No

A) Sí ¿Por qué?

B) $\mathrm{No}$
A) Sí ¿Por qué?
B) $\mathrm{No}$
A) Sí ¿Por qué?
B) No
A) Sí ¿Por qué?
A) $\mathrm{S}_{1}$
B) No 
La percepción de los funcionarios municipales sobre la reforma de 2014 al Fondo de Aportaciones para la Infraestructura Social

\begin{tabular}{c}
\hline Infraestructura básica educativa \\
\hline Mejoramiento de vivienda \\
\hline Caminos rurales \\
\hline Infraestructura productiva rural \\
\hline Gastos indirectos \\
\hline Desarrollo institucional \\
\hline Total 2014
\end{tabular}

3. Sobre la base de las prioridades de su municipio y / o el Plan Municipal de Desarrollo, ¿cómo considera el monto asignado de recursos con cargo al FAIs en cada uno de los programas durante 2014 ?

\begin{tabular}{cll}
\hline Agua potable & 1) Suficiente & 2) Insuficiente \\
\hline Alcantarillado & 1) Suficiente & 2) Insuficiente \\
\hline Drenaje y letrinas & 1) Suficiente & 2) Insuficiente \\
\hline Urbanización municipal & 1) Suficiente & 2) Insuficiente \\
\hline Electrificación rural y de colonias pobres & 1) Suficiente & 2)Insuficiente \\
\hline Infraestructura básica de salud & 1) Suficiente & 2) Insuficiente \\
\hline Infraestructura básica educativa & 1) Suficiente & 2) Insuficiente \\
\hline Mejoramiento de vivienda & 1) Suficiente & 2) Insuficiente \\
\hline Caminos rurales & 1) Suficiente & 2) Insuficiente \\
\hline Infraestructura productiva rural & 1) Suficiente & 2) Insuficiente \\
\hline Gastos indirectos & 1) Suficiente & 2) Insuficiente \\
\hline Desarrollo institucional & 1) Suficiente & 2) Insuficiente \\
\hline
\end{tabular}

4. ¿Utilizó la totalidad de recursos asignados en 2014 por concepto de FaIs para su municipio? 1) Sí 2) No (a pregunta 7) 5. ¿Hubo algún proyecto de inversión que no se realizó, y que hubiera querido financiar en 2014 con recursos del FAIs? 1) Sí 2) No (a pregunta 8)

6. ¿Me puede especificar qué proyecto o proyectos hubiera querido financiar en el 2014 con recursos del faIs?

7. ¿Cuál fue el motivo principal para no utilizar la asignación del FAIs en 2014?

8. ¿Cuál es el objetivo que persiguen en su municipio al aplicar los recursos del faIs? 
9. ¿Cómo determinaron en su municipio las obras que habrían de financiarse con cargo al FAIs en 2014 ?

10. ¿Emplearon recursos propios del municipio para complementar la obra financiada con cargo al FAIS en 2014 ?

1) Sí 2) No (a la pregunta 12)

11. ¿En qué programas emplearon recursos propios del municipio para complementar la obra financiada con cargo al FAIS en 2014? ¿Cuáles fueron los montos en cada programa?

Monto

\begin{tabular}{c}
\hline Agua potable \\
\hline Alcantarillado \\
\hline Drenaje y letrinas \\
\hline Urbanización municipal \\
\hline Electrificación rural y de colonias pobres \\
\hline Infraestructura básica de salud \\
\hline Infraestructura básica educativa \\
\hline Mejoramiento de vivienda \\
\hline Caminos rurales \\
\hline Infraestructura productiva rural \\
Gastos indirectos \\
\hline Desarrollo institucional
\end{tabular}

12. De acuerdo con su PERCEPCIÓN y la EXPERIENCIA que ha tenido en su municipio, le pedimos calificar los distintos programas del FAIs de acuerdo con el impacto en reducir la pobreza. Asigne una calificación del 1 al 10 a cada programa, donde 10 significa el mayor impacto para reducir la pobreza y 1 significa el menor impacto en la reducción de pobreza.

\begin{tabular}{cc}
\hline Proyecto & Calificación \\
\hline Agua potable & \\
\hline Alcantarillado \\
\hline Drenaje y letrinas \\
\hline Urbanización municipal \\
\hline Electrificación rural y de colonias pobres
\end{tabular}


La percepción de los funcionarios municipales sobre la reforma de 2014 al Fondo de Aportaciones para la Infraestructura Social

\begin{tabular}{c}
\hline Infraestructura básica de salud \\
\hline Infraestructura básica educativa \\
\hline Mejoramiento de vivienda \\
\hline Caminos rurales \\
\hline Infraestructura productiva rural \\
Gastos indirectos \\
\hline Desarrollo institucional
\end{tabular}

13. En el programa de (programa con mayor calificación de la pregunta 12), queremos saber en particular cuál es la acción y área con mayor impacto en la pobreza.

\begin{tabular}{cc}
\hline Acción: & Área: \\
\hline Construcción & a) Rural \\
\hline Rehabilitación & b) Urbana \\
\hline Ampliación & \\
\hline Equipamiento &
\end{tabular}

14. ¿Considera que existen otros programas, diferentes a los contemplados para asignar los recursos del FAIs, que por su impacto en la reducción de pobreza debieran ser considerados para usar los recursos del faIs? 1) Sí 2) No (a pregunta 16)

15. ¿Qué otros programas considera usted se le deberían de asignar recursos del FAIS por su impacto en la reducción de pobreza? ProfundizAR

\begin{tabular}{c}
\hline Programa 1 \\
\hline Programa 2 \\
\hline Programa 3 \\
\hline
\end{tabular}

16. ¿Considera que el FaIs es la mejor forma de reducir la pobreza en su municipio? 1) Sí 2) No

16.1 ¿Por qué razón usted (respuesta de la pregunta anterior) considera que el FAIs es la mejor forma de reducir la pobreza en su municipio? 


\section{Sección III. Indicadores de resultado, impacto y seguimiento}

17. ¿Miden en su municipio los resultados de los programas financiados con cargo al fars? 1) Sí 2) No (a pregunta 19)

18. ¿Podría decirnos qué indicadores utilizan para medir los resultados en cada uno de los programas?

\begin{tabular}{c}
\hline Programa \\
\hline Agua potable \\
\hline Alcantarillado \\
\hline Drenaje y letrinas \\
\hline Urbanización municipal \\
\hline Electrificación rural y de colonias pobres \\
\hline Infraestructura básica de salud \\
\hline Infraestructura básica educativa \\
\hline Mejoramiento de vivienda \\
\hline Caminos rurales \\
\hline Infraestructura productiva rural \\
\hline Gastos indirectos \\
\hline Desarrollo institucional
\end{tabular}

19. ¿Miden en su municipio los impactos de los programas financiados con cargo al faIs? 1) Sí 2) No (a pregunta 21) 20. ¿Podría decirnos qué indicadores utilizan para medir los impactos en cada uno de los programas?

\begin{tabular}{c}
\hline Programa \\
\hline Agua potable \\
\hline Alcantarillado \\
\hline Drenaje y letrinas \\
\hline Urbanización municipal \\
\hline Electrificación rural y de colonias pobres \\
\hline Infraestructura básica de salud \\
\hline Infraestructura básica educativa \\
\hline Mejoramiento de vivienda \\
Caminos rurales \\
\hline Infraestructura productiva rural \\
Gastos indirectos \\
\hline Desarrollo institucional
\end{tabular}


La percepción de los funcionarios municipales sobre la reforma de 2014 al Fondo de Aportaciones para la Infraestructura Social

21. ¿Dan seguimiento en su municipio a los programas financiados con cargo al faIs? 1) Sí 2) No (a pregunta 23) 22. ¿Podría decirnos qué procedimientos siguen y los indicadores empleados en el seguimiento?

\begin{tabular}{ll}
\hline Procedimiento 1 & Indicador 1 \\
\hline Procedimiento 2 & Indicador 2 \\
\hline
\end{tabular}

23. Evalúan en su municipio los programas que se financian con recursos del faIs? 1) Sí 2) No (a pregunta 25)

24. ¿Podría explicarnos cómo hacen para evaluar los programas que financian con recursos del faIs?

25. ¿Considera que los recursos del FaIs que se han usado en su municipio han reducido la pobreza? 1) Sí 2) No

\section{Sección IV. La fórmula de asignación}

26. ¿Considera adecuado que el FAIs se asigne a través de una fórmula, tal como se hace actualmente en México?
a) Sí (a pregunta 28)
b) No

27. ¿Qué otro esquema considera adecuado para asignar el FAIS entre las entidades federativas?, ¿y entre los MUNICIPIOS de cada entidad federativa?

28. ¿Qué factores/variables considera que deben ser empleados para distribuir el FAIs?

29. ¿Conoció la fórmula que se usó para asignar los recursos del faIs entre los estados mexicanos hasta 2013? 1) Sí 2) No 30. ¿Conoció la fórmula que se usó para asignar los recursos del FAIs a su municipio hasta 2013? 1) Sí 2) No 
31. ¿Conoce la fórmula que se usa desde 2014 para asignar los recursos del faIs entre los estados mexicanos? 1) Sí 2) No 32. ¿Conoce la fórmula que se usa desde 2014 para asignar los recursos del fais a su municipio? 1) Sí 2) No

Si las respuestas a las preguntas 29 y 31 es Sí.

32 ¿Usted considera adecuado que se haya modificado la fórmula de asignación al FAIs? 1) Sí 1) No

32.1 ¿Por qué razón considera usted que (respuesta de la pregunta anterior) debió modificarse la fórmula de asignación del FaIs?

Como usted sabe, el incremento del FAIs se asigna dando un peso de $20 \%$ a la eficacia en la reducción de la pobreza y un $80 \%$ a las carencias de la entidad. Si la decisión de esos pesos dependiera de usted,

33. ¿Cuál en su opinión, debería ser el peso adecuado para la eficacia en la reducción de la pobreza y el adecuado para el número de carencias de la población? (Escribir un porcentaje del 0 al 100\% para cada una. La suma debe dar 100\%)

\begin{tabular}{cc}
\hline & Porcentaje \\
\hline Reducción de pobreza & \\
\hline Número de carencias de la población \\
\hline Total
\end{tabular}

34. ¿Considera usted que habría oposición en su estado/ municipio si el 100\% del FAIs se distribuyera sobre la base de la eficacia en la reducción de la pobreza? 1) Sí () 2) No () 34.1 ¿Por qué razón usted (respuesta de la pregunta anterior) que habría oposición?

35. ¿La fórmula que se usa a escala nacional para asignar el FAIs entre los estados es la misma que se usa en su Estado para asignar el FAIs entre los municipios? 1) Sí (pasar a pregunta 37) 2) No

36. ¿Qué factores incluye la fórmula con la que se distribuye el FAISM en su estado? 
37. La fórmula que se utiliza para asignar los recursos del FAIS a su municipio ¿Incluye alguna variable que mida la magnitud de la pobreza con relación a los municipios del estado? 1) Sí 2) No (pasar a pregunta 39)

38. ¿Considera que el hecho de que incluya alguna variable que mida la magnitud de pobreza, provoca que el municipio no reduzca la pobreza con el objeto de recibir una mayor cuantía de recursos? 1) Sí 2) No

38.1 ¿Me puede decir por qué lo considera así?

\section{v. Sobre la reforma de 2014}

39. ¿Conoce los cambios en la Ley de Coordinación Fiscal que entraron en vigor a partir del 1 de enero de 2014 con relación al fais? 1) Sí 2) No (a pregunta 41)

40. A continuación le presentamos un conjunto de afirmaciones sobre las reformas al FAIs (artículos 32 a 35 de la Ley de Coordinación Fiscal) que entraron en vigor a partir del 1 de enero de 2014. Por favor indique que tan de acuerdo se encuentra con las siguientes afirmaciones, donde 1 es completamente de acuerdo y 4 completamente en desacuerdo.

\begin{tabular}{|c|c|c|c|c|}
\hline & 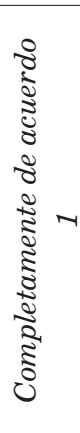 & $\begin{array}{c}0 \\
0 \\
0 \\
0 \\
0 \\
0 \\
0 \\
0\end{array}$ & 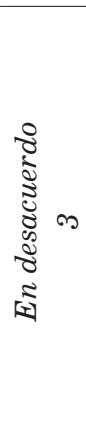 & 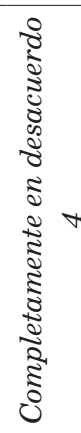 \\
\hline \multicolumn{5}{|l|}{ La nueva fórmula de asignación } \\
\hline \multicolumn{5}{|l|}{ Incentiva a reducir la pobreza en el municipio } \\
\hline \multicolumn{5}{|l|}{ Mejora la distribución de los recursos del fAIs } \\
\hline \multicolumn{5}{|l|}{ Mejora el destino de los recursos del FAIs } \\
\hline \multicolumn{5}{|l|}{ Mejora el ejercicio de los recursos del faIs } \\
\hline Refuerza los objetivos de creación del FAIS & & & & \\
\hline
\end{tabular}




\begin{tabular}{|c|c|c|c|}
\hline & 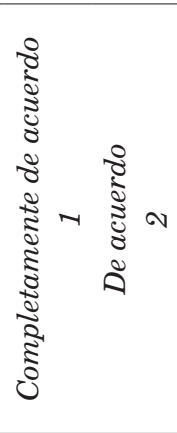 & 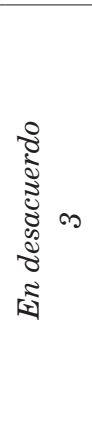 & 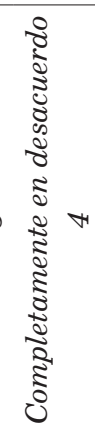 \\
\hline Asegura un mejor uso de los recursos del faIs & & & \\
\hline $\begin{array}{c}\text { Asegura una mayor transparencia en la } \\
\text { distribución de los recursos a las entidades } \\
\text { federativas y municipios }\end{array}$ & & & \\
\hline $\begin{array}{c}\text { Reducirá los recursos financieros a los } \\
\text { municipios más pobres }\end{array}$ & & & \\
\hline $\begin{array}{l}\text { Establece con claridad el destino de los } \\
\text { recursos del fondo }\end{array}$ & & & \\
\hline $\begin{array}{l}\text { Hace previsible que se obtengan mejores } \\
\text { resultados en la aplicación de los recursos }\end{array}$ & & & \\
\hline $\begin{array}{l}\text { Promueve la eficiencia en el ejercicio de los } \\
\text { recursos }\end{array}$ & & & \\
\hline $\begin{array}{l}\text { Es más claro el cálculo de la asignación de } \\
\text { fondos a los estados }\end{array}$ & & & \\
\hline $\begin{array}{l}\text { Es más claro el cálculo de la asignación de } \\
\text { fondos a los municipios }\end{array}$ & & & \\
\hline La información usada es más oportuna & & & \\
\hline $\begin{array}{l}\text { Ha reducido el monto nominal que recibimos } \\
\text { del Fondo }\end{array}$ & & & \\
\hline $\begin{array}{l}\text { Ha reducido el monto real que recibimos del } \\
\text { Fondo }\end{array}$ & & & \\
\hline Con el nuevo esquema para operar el FAIs & & & \\
\hline La operación de los recursos es más sencilla & & & \\
\hline Es más sencillo bajar los fondos federales & & & \\
\hline La operación será más transparente & & & \\
\hline $\begin{array}{c}\text { Los fondos deben estar mejor focalizados para } \\
\text { la reducción de la pobreza en el municipio }\end{array}$ & & & \\
\hline $\begin{array}{l}\text { Los fondos son más predecibles y facilitan la } \\
\text { planeación municipal }\end{array}$ & & & \\
\hline
\end{tabular}


La percepción de los funcionarios municipales sobre la reforma de 2014 al Fondo de Aportaciones para la Infraestructura Social

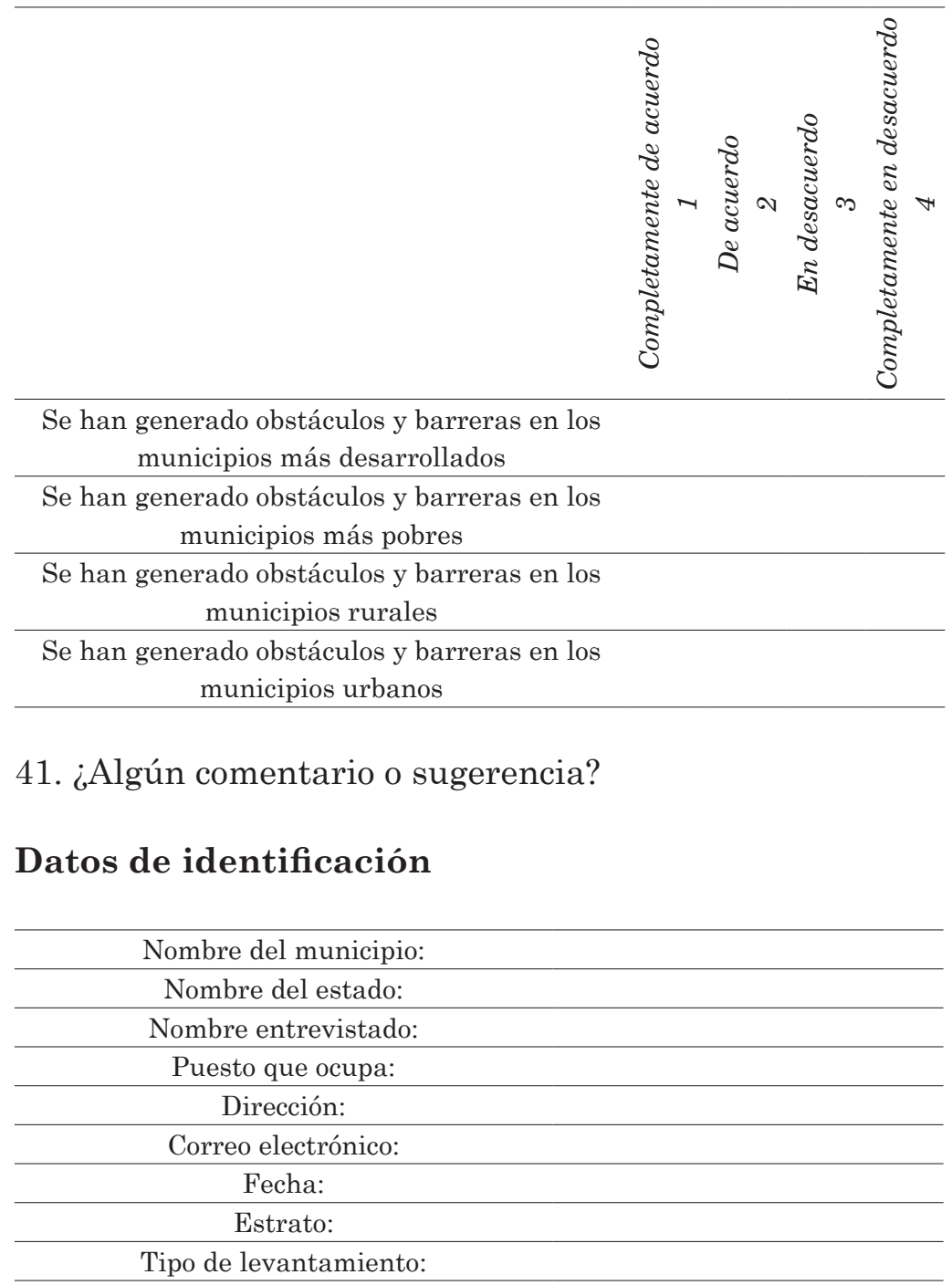

